\title{
The pro-fibrotic properties of transforming growth factor on human fibroblasts are counteracted by caffeic acid by inhibiting myofibroblast formation and collagen synthesis
}

\author{
Masum M. Mia ${ }^{1} \cdot$ Ruud A. Bank ${ }^{1}$ \\ Received: 2 April 2015 / Accepted: 26 August 2015 / Published online: 9 October 2015 \\ (C) The Author(s) 2015. This article is published with open access at Springerlink.com
}

\begin{abstract}
Fibrosis is a chronic disorder affecting many organs. A universal process in fibrosis is the formation of myofibroblasts and the subsequent collagen deposition by these cells. Transforming growth factor betal (TGF $\beta 1$ ) plays a major role in the formation of myofibroblasts, e.g. by activating fibroblasts. Currently, no treatments are available to circumvent fibrosis. Caffeic acid phenethyl ester (CAPE) shows a broad spectrum of biological activities, including anti-fibrotic properties in vivo in mice and rats. However, little is known about the direct effects of CAPE on fibroblasts. We have tested whether CAPE is able to suppress myofibroblast formation and collagen formation of human dermal and lung fibroblasts exposed to TGF $\beta 1$, and found that this was indeed the case. In fact, the formation of myofibroblasts by TGF $\beta 1$ and subsequent collagen formation was completely abolished by CAPE. The same was observed for fibronectin and tenascin C. The lack of myofibroblast formation is likely due to the suppression of GLII and GLI2 expression by CAPE because of diminished nuclear SMAD2/3 levels. Posttreatment with CAPE after myofibroblast formation even resulted in a partial reversal of myofibroblasts into fibroblasts and/or reduction in collagen formation. Major discrepancies were seen between mRNA levels of collagen type I and cells stained positive for collagen, underlining the need for protein data in fibrosis studies to make reliable conclusions.
\end{abstract}

Ruud A. Bank

R.A.Bank@umcg.nl

1 Department of Pathology \& Medical Biology, University of Groningen, University Medical Center Groningen, Hanzeplein 1, 9713 GZ Groningen, The Netherlands
Keywords Fibrosis · Collagen · Myofibroblasts · Caffeic acid · Lysyl hydroxylase

\section{Introduction}

Caffeic acid phenethyl ester (CAPE) is a polyphenolic compound with major anti-inflammatory, anti-fibrotic, antioxidant and immune-modulatory properties (Tolba et al. 2013; Murtaza et al. 2014). CAPE is one of the active compounds of honeybee propolis (Banskota et al. 2001), and has been tested in vivo in a variety of fibrosis-related models in rats and mice (Larki et al 2013; Tomur et al. 2011; Ogeturk et al. 2005; Özyurt et al. 2004; Zhao et al. 2014; Chuang et al. 2014, 2015). These studies showed a protective effect of CAPE, i.e. it attenuated the hallmark of fibrosis, namely excessive collagen deposition. Collagen is produced by myofibroblasts (Goldsmith et al. 2014; Mallat et al. 2013), and the in vivo studies indeed revealed a decrease in the amount of alpha-smooth muscle actin ( $\alpha$ SMA)-positive cells, a marker that is widely used to detect myofibroblasts. However, little is known about the mechanisms behind the antifibrotic properties of CAPE. Fibrosis is an end result of the tissue repair process, and in this process a variety of inflammatory cells are involved, cells that secrete during the course of healing various cytokines that stimulate myofibroblast formation. Because of the many different inhibitory properties of CAPE shown in vivo and in vitro, animal studies cannot reveal whether CAPE directly acts on fibroblasts. Thus, it is not known if the decrease in myofibroblast numbers seen in vivo is an effect of the anti-inflammatory or immuno-modulatory properties of CAPE, or, alternatively, whether CAPE also directly affects the transformation of fibroblasts into myofibroblasts. 
To the best of our knowledge, only some fragmentary information is available on the direct effect of CAPE on fibroblasts regarding expression/synthesis of collagen type I and $\alpha$ SMA. Murine lung fibroblasts (L929 cell line) exposed to bleomycin exhibited increased levels of collagen production (as measured by the collagen-specific amino acid hydroxyproline in the culture medium); this was not the case when the cells were first pretreated with CAPE (Liu et al. 2013). On the other hand, NIH 3 T3 murine cells treated with CAPE showed an increase of intracellular collagen levels (Song et al. 2008). Hepatic stellate cells of Wistar rats exposed to CAPE showed a decreased collagen type I gene expression (Zhao et al. 2003). Finally, human nasal polyp-derived fibroblasts treated with TGF $\beta 1$ showed increased gene and protein levels of $\alpha$ SMA and collagen types I and III; this was inhibited by pretreating the fibroblasts with CAPE (Chun et al. 2014).

Transforming growth factor betal (TGF $\beta 1$ ) is one of the strongest pro-fibrotic cytokines (Ghosh et al. 2013; Yue et al. 2010). Fibroblasts stimulated with TGF $\beta 1$ rapidly transform into myofibroblasts and start to produce large amounts of collagen type I (Goldsmith et al. 2014; Mallat et al. 2013). In the current study, we have stimulated human adult dermal (HDFa) and human adult lung (HLFa) fibroblasts with TGF $\beta 1$ in the presence or absence of CAPE, and investigated the expression and/or synthesis of cytoskeletal components, collagen type I, the collagen-modifying enzyme lysyl hydroxylase 2 (LH2), and the transcription factors GLI1, GLI2, and SNAIL. In addition, we investigated whether myofibroblasts that are formed by TGF $\beta 1$ can be reversed into fibroblasts by a post-treatment with CAPE.

\section{Materials and methods}

\section{Cell culture}

HDFa [Caucasian, 20 years, CCD-1093Sk (ATCC ${ }^{\circledR}$ CRL$2115^{\mathrm{TM}}$ ), ATCC, USA] and HLFa [Caucasian, 27 years, CCD-19Lu (ATCC ${ }^{\circledR}$ CCL-210 ${ }^{\mathrm{TM}}$ ), ATCC, USA] were cultured in basal medium [= Eagle's minimal essential medium (BE12-662F; Lonza, Switzerland) containing $1 \%$ l-glutamine (Lonza), $1 \%$ penicillin/streptomycin (Gibco Life Technologies, UK)] supplemented with $10 \%$ fetal bovine serum (FBS) (Thermo Scientific, USA). Passages 5-10 of HDFa and HLFa were seeded with a density of 15,000 cells $/ \mathrm{cm}^{2}$ in a Costar 12-well plate (for quantitative real time polymerase chain reaction) or in a 48-well plate/8-well chamber slides (Corning, USA; for immunofluorescence staining). After $72 \mathrm{~h}$, fibroblasts were washed with phosphate-buffered saline (PBS), starved overnight in basal medium supplemented with $0.5 \%$ FBS, treated for $30 \mathrm{~min}$ in basal medium supplemented with $0.17 \mathrm{mM}$ L-ascorbic acid 2-phosphate magnesium salt (A-8960; Sigma, USA) and 0.5\% FBS with/without CAPE
(5 $\mu \mathrm{g} / \mathrm{ml})$ (2743; Tocris, UK), and subsequently cultured for $48 \mathrm{~h}$ in basal medium supplemented with $0.17 \mathrm{mM} \mathrm{L}$-ascorbic acid 2-phosphate magnesium salt and $0.5 \% \mathrm{FBS}$ with/without recombinant human TGF $\beta 1$ (10 ng/ml) (100-21; Peprotech, $\mathrm{UK})$ in the presence/absence of CAPE $(5 \mu \mathrm{g} / \mathrm{ml})$. In another experiment, the fibroblasts that were starved overnight were stimulated with basal medium supplemented with $0.17 \mathrm{mM} \mathrm{L-}$ ascorbic acid 2-phosphate magnesium salt and $0.5 \%$ FBS with/without TGF $\beta 1(10 \mathrm{ng} / \mathrm{ml})$ for $48 \mathrm{~h}$, followed by a post-treatment with basal medium supplemented with $0.17 \mathrm{mM}$ L-ascorbic acid 2-phosphate magnesium salt and $0.5 \% \mathrm{FBS}$ with/without CAPE $(5 \mu \mathrm{g} / \mathrm{ml})$ for $24 \mathrm{~h}$. Subsequently, whole-cell lysates (as obtained with FARB Buffer; Favorgen Biotech, Taiwan) were used for quantitative real time polymerase chain reaction (qRT-PCR). For immunofluorescence studies, cells were washed with PBS and fixed with methanol/acetone (1:1 ratio; Merck, Germany) for $5 \mathrm{~min}$. The CAPE compound was dissolved in absolute ethanol (vehicle) at a concentration of $25 \mu \mathrm{g} / \mu \mathrm{l}$. All cell culture protocols were performed at $37{ }^{\circ} \mathrm{C}$ in a humidified $5 \% \mathrm{CO}_{2}$ environment.

\section{RNA isolation, cDNA synthesis and qRT-PCR}

Total RNA was isolated using the Favorgen RNA extraction kit (Favorgen Biotech) according to the manufacturer's protocol. The concentration and quality of RNA was measured with UV spectrophotometry (NanoDrop Technologies, Wilmington, NC, USA). For the synthesis of cDNA, total RNA was reverse transcribed with the First Strand cDNA synthesis kit (Fermentas, Lithuania) according to the manufacturer's protocol. Gene expression analysis was performed by means of qRT-PCR in a $10-\mu 1$ reaction mixture containing 10 ng cDNA, SYBR Green Master Mix (Roche, USA), $6 \mu \mathrm{M}$ forward primer and $6 \mu \mathrm{M}$ reverse primer (for primer sequences, see Table 1). qRT-PCR was conducted in triplicate for each condition in a 384-well plate at $95^{\circ} \mathrm{C}$ for $15 \mathrm{~s}$ and $60^{\circ} \mathrm{C}$ for $1 \mathrm{~min}$ for 40 cycles using the ViiA 7 Real-Time PCR System (Applied Biosystems, USA). Data were analyzed with the ViiA 7 Real-Time PCR System Software (Applied Biosystems). All mRNA data were normalized against the reference gene tyrosine 3-monooxygenase/tryptophan 5-monooxygenase activation protein, zeta isoform (YWHAZ).

\section{Immunofluorescence staining}

After methanol/acetone fixation, fibroblasts were washed and incubated with primary antibodies (Table 2) diluted in PBS containing $2 \%$ bovine serum albumin (BSA) (K1106; Sanquin, Netherlands) for $1 \mathrm{~h}$ at RT. After washing with PBS, cells were incubated for $30 \mathrm{~min}$ at RT with biotinylated secondary antibodies (Table 3 ) diluted in PBS containing $2 \%$ BSA for $30 \mathrm{~min}$ at RT. The cells were washed again and incubated with streptavidin-CY3 (Invitrogen, USA) (1:100) 
Table 1 List of primer sequences used for qRT-PCR

\begin{tabular}{lll}
\hline Gene & Forward sequence & Reverse sequence \\
\hline ACTA2 & CTGTTCCAGCCATCCTTCAT & TCATGATGCTGTTGTAGGTGGT \\
$T A G L N$ & GGCCAAGGCTCTACTGTCTG & CCCTTGTTGGCCATGTCT \\
$C O L 1 A 1$ & GGGATTCCCTGGACCTAAAG & GGAACACCTCGCTCTCCA \\
$C O L 1 A 2$ & CTGGAGAGGCTGGTACTGCT & AGCACCAAGAAGACCCTGAG \\
$P L O D 2$ & ATGGAAATGGACCCACCAA & TGCAGCCATTATCCTGTGTC \\
GLI1 & CAGGGAGGAAAGCAGACTGA & ACTGCTGCAGGATGACTGG \\
GLI2 & CACGCTCTCCATGATCTCTG & CCCCTCTCCTTAAGGTGCTC \\
SNAIL1 & GCTGCAGGACTCTAATCCAGA & ATCTCCGGAGGTGGGATG \\
$F N 1$ & CTGGCCGAAAATACATTGTAAA & CCACAGTCGGGTCAGGAG \\
$T N C$ & CCGGACCAAAACCATCAGT & GGGATTAATGTCGGAAATGGT \\
YWHAZ & GATCCCCAATGCTTCACAAG & TGCTTGTTGTGACTGATCGAC \\
\hline
\end{tabular}

in PBS containing $1 \%$ BSA and DAPI $(1: 10,000)$ for $30 \mathrm{~min}$. After washing with PBS, cell culture wells were mounted with Citifluor (Agar Scientific, UK) and the staining pattern was visualized with fluorescence imaging microscopy (TissueFAXS; TissueGnostics, Austria). TissueFAXS data was analyzed with the TissueQuest software as described previously (Mia et al. 2014).

\section{Nuclear/cytoplasmic localization of SMAD2/3}

HDFa and HLFa were cultured for 45 min in the presence of CAPE alone, TGF $\beta 1$ alone, or TGF $\beta 1$ in combination with CAPE. After treatment, cells were washed with ice-cold PBS and fixed with methanol/acetone (1:1) for $5 \mathrm{~min}$. Subsequently, cells were washed with PBS and incubated with polyclonal goat anti-human to SMAD2/3 (AF3797; R\&D, UK) diluted to $15 \mu \mathrm{g} / \mathrm{ml}$ in PBS containing $2 \%$ bovine serum albumin (BSA) (K1106; Sanquin, Netherlands) for $3 \mathrm{~h}$ at $4{ }^{\circ} \mathrm{C}$. After washing with PBS, cells were incubated with biotinylated secondary antibody rabbit anti-goat (6160-08; SouthernBiotech, USA) diluted in PBS containing $2 \%$ BSA for $30 \mathrm{~min}$ at RT. The cells were washed again and incubated for 30 min with streptavidin-CY3 (Invitrogen) (1:100) in PBS containing $1 \%$ BSA and DAPI $(1: 10,000)$. After washing with PBS, cell culture wells were mounted with Citifluor (Agar Scientific) and the staining pattern was visualized by using confocal laser scanning microscopy (Leica TCS SP8; Leica Microsystems, Germany).

\section{Statistics}

All mRNA and immunofluorescence data are presented as mean \pm SEM for at least three independent experiments. Results were analysed with either one-way analysis of variance (ANOVA) followed by Tukey's post-test or two-tailed unpaired $t$ test analysis using Graph-Pad Prism v.5 (GraphPad Software, USA). $P<0.05$ was considered to be statistically significant.

\section{Results}

\section{Basal levels of mRNA and protein in unstimulated HDFa and HLFa}

There were major differences in the basal expression levels between HDFa and HLFa (Fig. 1). In HLFa, a higher expression was seen of ACTA2 (Fig. 1a), TAGLN (Fig. 1b), GLI1 (Fig. 1c), GLI2 (Fig. 1d), COL1A2 (Fig. 1f), and PLOD2 (Fig. 1g) compared to HDFa (a 4-fold, 5-fold, 10-fold, 2-fold, 2-fold and 4-fold difference, respectively). The basal expression of COL1A1 was slightly, but significantly, lower in HLFa compared to HDFa (Fig. 1e). The major differences in basal
Table 2 List of primary antibodies used for immunofluorescence analysis

\begin{tabular}{lll}
\hline Antigen (target protein) & Antibody (dilution) & Source (Cat. \#, Company) \\
\hline$\alpha$ SMA & Mouse monoclonal IgG2a (1:100) & M0851, Dako, Denmark \\
SM22 $\alpha$ & Polyclonal rabbit IgG $(1: 200)$ & ab14106, Abcam, UK \\
Collagen type I & Mouse monoclonal IgG1 (1:300) & ab90395, Abcam, UK \\
LH2 & Mouse polyclonal IgG $(1: 100)$ & SAB1400213, Sigma, USA \\
Fibronectin & Rabbit polyclonal IgG $(1: 400)$ & ab6584, Abcam, UK \\
Tenascin C & Mouse monoclonal IgG1 $(1: 100)$ & ab6393, Abcam, UK \\
SMAD2/3 & Polyclonal goat IgG $(15 \mu \mathrm{g} / \mathrm{ml})$ & AF3797, R\&D, UK \\
\hline
\end{tabular}


Table 3 List of secondary antibodies used for immunofluorescence analysis

\begin{tabular}{lll}
\hline Antigen (target protein) & Biotinylated secondary antibody (dilution 1:100) & Source (Cat. \#, Company) \\
\hline$\alpha$ SMA & Goat-anti-mouse IgG2a & 1080-08, SouthernBiotech, USA \\
SM22 $\alpha$ and fibronectin & Goat anti-rabbit IgG & E0432, Dako, Denmark \\
Collagen type I and tenascin C & Goat-anti-mouse IgG1 & 1071-08, SouthernBiotech, USA \\
LH2 & Goat-anti-mouse IgG & 1030-08, SouthernBiotech, USA \\
Smad2/3 & Rabbit-anti-goat IgG & $6160-08$, SouthernBiotech, USA \\
\hline
\end{tabular}

expression were also reflected in the protein stainings for $\alpha$ SMA, SM22 $\alpha$, collagen I and LH2: the \% cells that stained positive for these proteins was always higher in HLFa than HDFa (6-fold, 2-fold, 20-fold and 2.5-fold difference, respectively) (Fig. 1h-s).

\section{Effect of TGF $\beta 1$ and CAPE on nuclear localization of SMAD2/3}

Staining for SMAD2/3 showed a predominantly cytoplasmic localization in HDFa (Fig. 2a-c) and HLFa (Fig. 2d-f), a pattern that was dramatically shifted towards a nuclear localization when the cells were stimulated with TGF $\beta 1$ (Fig. 2b, e). CAPE clearly inhibited the nuclear translocation of SMAD2/3 (Fig. 2c, f). These observations are in line with that of Chuang et al. (2014, 2015).

\section{Effect of TGF $\beta 1$ and CAPE on ACTA2 ( $\alpha$ SMA)}

In order to differentiate the fibroblasts into myofibroblasts, the cells were stimulated for $48 \mathrm{~h}$ with TGF $\beta 1$. Both HDFa and HLFa showed a major increase ( $>6$-fold) in mRNA levels of ACTA2 (encoding for the protein $\alpha \mathrm{SMA}$ ) (Fig. 3a, b), as was the case for the number of cells stained positive for $\alpha \mathrm{SMA}(>$ 10 -fold increase) (Fig. 3e, i, k, l). Interestingly, the addition of CAPE resulted in a suppression to baseline levels, both on an mRNA level (Fig. 3a, b) and on a protein level (Fig. 3f, j-1). Incubation of CAPE alone (thus without the addition of TGF $\beta 1$ ) also suppressed the mRNA and protein level in $\mathrm{LFa}$, as these cells show, in contrast to HDFa, already at baseline in some $\alpha$ SMA positive cells (Fig. $3 \mathrm{a}-\mathrm{d}, \mathrm{g}, \mathrm{h}, \mathrm{k}, \mathrm{l}$ ). Thus, CAPE is able to inhibit the formation of TGF $\beta 1$-induced $\alpha$ SMA stress fiber formation. CAPE is, in addition, able to disrupt the already existing $\alpha$ SMA stress fibers seen in HLFa. However, a post-treatment with CAPE did not result in a decrease of the TGF $\beta 1$-induced $\alpha$ SMA stress fibers in HLFa, although a partial decrease was seen in HDFa under the same conditions (Fig. 4a-f).

\section{Effect of TGF $\beta 1$ and CAPE on TAGLN (SM22 $\alpha)$}

Another cytoskeletal element, SM22 $\alpha$ (encoded by TAGLN) showed similar results. mRNA was upregulated with TGF $\beta 1$
(HDFa: >10-fold; HLFa: 2-fold), an upregulation that was suppressed by CAPE, but reaches baseline levels only in HLFa (Fig. 5a, b). Stress fibers were upregulated with TGF $\beta 1$ as well, as indicated by a 2 -fold increase in the $\%$ of cells that stain positive for SM22 $\alpha$. CAPE suppressed the number of positive cells to baseline levels, both for HDFa and HLFa (Fig. 5c-1). CAPE alone had an effect only on the number of positive cells that were present before TGF $\beta 1$ stimulation in HDFa (Fig. 5c, d, k).

\section{Effect of TGF $\beta 1$ and CAPE on collagen type I expression/formation}

We next investigated whether CAPE was able to inhibit collagen type I expression/formation. TGF $\beta 1$ increased the expression of COL1A1 and COL1A2 in HFDa and HLFa (7- and 5-fold and 2- and 3-fold, respectively) (Fig. 6a-d). CAPE did not inhibit the expression of COL1A1 in HDFa (Fig. 6a), and increased the expression of COL1A2 $>2$-fold (Fig. 6b). In contrast, CAPE inhibited the expression of COL1A1 in HLFa to baseline levels (Fig. 6c), and slightly inhibited the expression of COL2A1 (but not to baseline levels) (Fig. 6d). At the protein level, a different picture emerged: in both HDFa and HLFa, the \% cells stained positive for collagen type I was dramatically reduced by CAPE. The few collagen-positive cells of HLFa were present before TGF $\beta 1$ stimulation also disappeared (Fig. 6e-n). Post-treatment with CAPE after TGF $\beta 1$ stimulation resulted in a major decrease in collagenproducing cells (HDFa: 5-fold decrease; HLFa: 2-fold decrease) (Fig. 7a-f).

\section{Effect of TGF $\beta 1$ and CAPE on PLOD2 (LH2)}

In fibrotic collagen, increased amounts are seen of crosslinks derived from hydroxylysine, a cross-link that is catalyzed LH2 (van der Slot 2004, 2005a; Yamauchi 2012). mRNA of PLOD2, encoding for LH2, was 15 fold and 4-fold upregulated after TGF $\beta 1$ stimulation in HDFa and HLFa, respectively (Fig. 8a, b). Both cell types reacted quite differently towards CAPE with respect to $P L O D 2$. In HDFa, PLOD2 mRNA levels were more than 10-fold upregulated compared to the mRNA levels seen with TGF $\beta 1$ alone (Fig. 8a); in HLFa, this increase was 

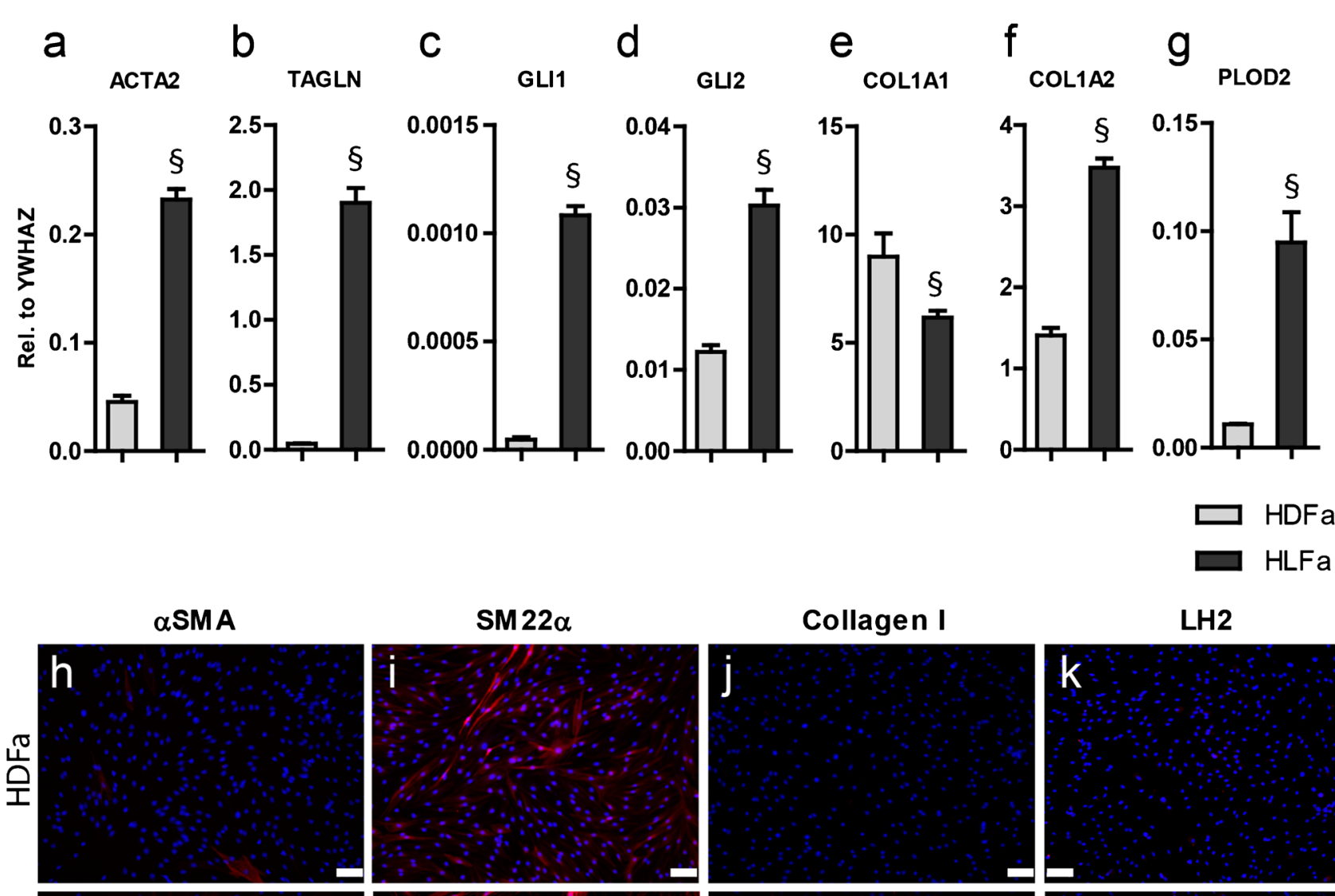

$\square \mathrm{HDFa}$

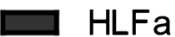

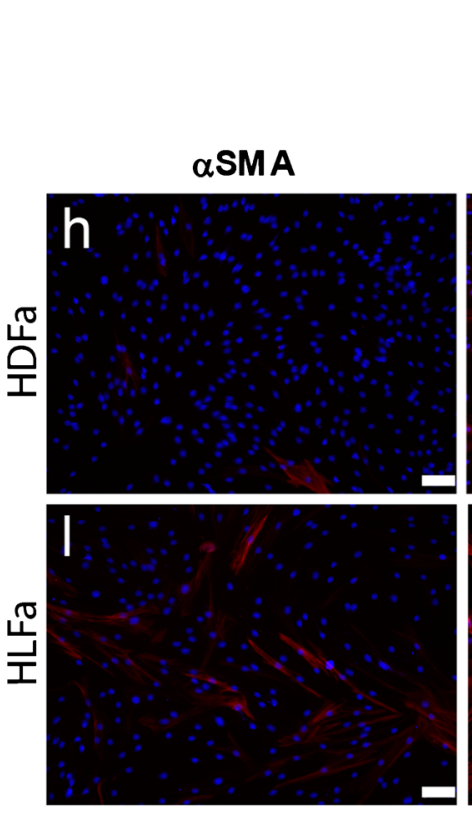
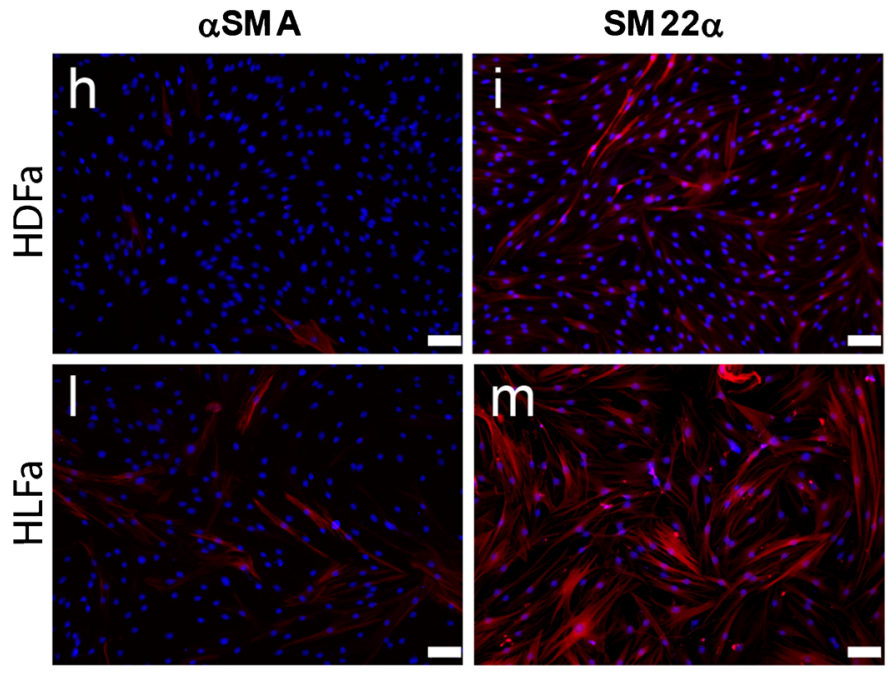

$p$

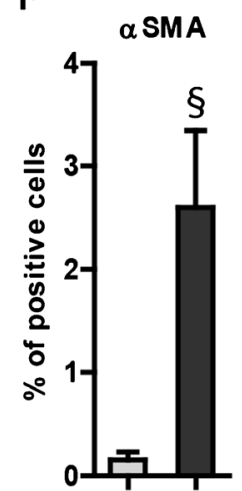

Fig. 1 Characterization of mRNA levels and protein synthesis as observed in non-activated HDFa and HLFa. Fibroblasts were cultured for $48 \mathrm{~h}$ in basal medium supplemented with $0.17 \mathrm{mM} \mathrm{L}$-ascorbic acid 2-phosphate magnesium salt and $0.5 \%$ FBS in the absence of TGF $\beta 1$ and CAPE. a-g mRNA levels of ACTA2, TAGLN, GLI1, GLI2, COL1A1,

$<2$-fold (Fig. 8b). Cells that were not stimulated with TGF $\beta 1$ also showed an upregulation of PLOD2 when
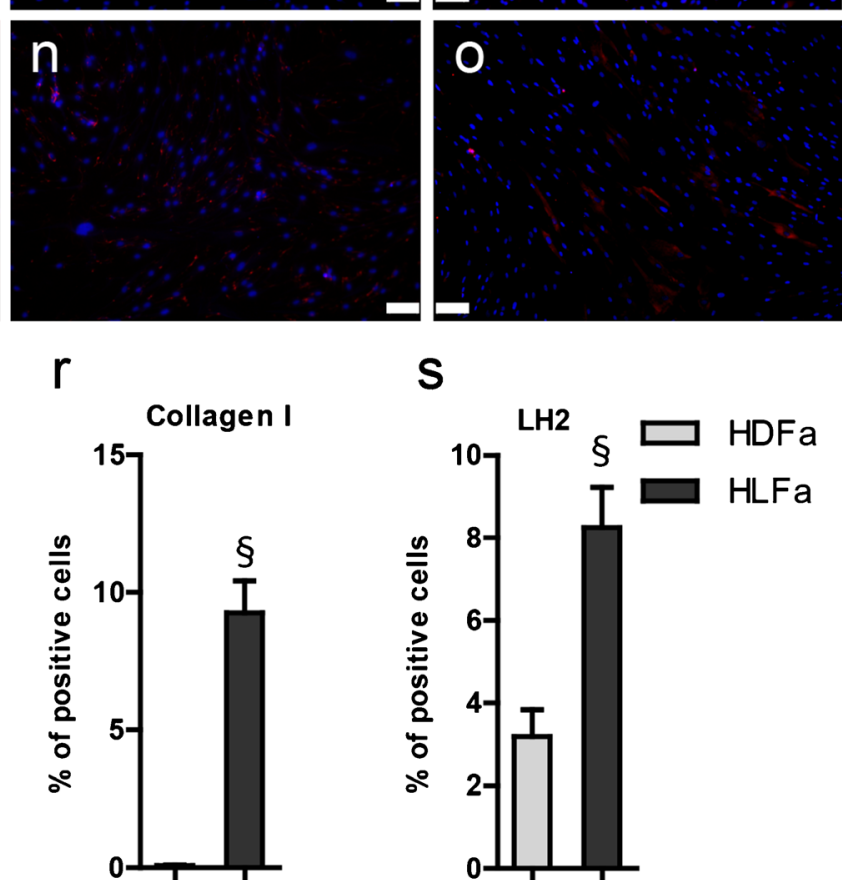

COL1A2 and PLOD2 relative to the reference gene $Y W H A Z$. $\mathbf{h}-\mathbf{0}$ Representative immunofluorescence stainings (upper panel) and $\mathbf{p}-\mathbf{s}$ quantification of the $\%$ of cells (lower panel) positive for $\alpha$ SMA, SM22 $\alpha$, collagen type I and LH2. § Statistically significant towards HDFa. Scale bar $100 \mu \mathrm{m}$

incubated with CAPE: the induction was about 40 -fold in HDFa and 2-fold in HLFa (Fig. 8a, b). The increase 
Fig. 2 Effects of TGF $\beta 1$ and

CAPE on nuclear localization of $\mathrm{SMAD2} / 3$. a-c HDFa and $\mathbf{d}-\mathbf{f}$

HLFa were cultured for $45 \mathrm{~min}$ in the presence of TGF $\beta 1$ alone, or TGF $\beta 1$ in combination with

CAPE (co-treatment). Fibroblasts cultured in the presence of

TGF $\beta 1$ showed a strong nuclear localization of SMAD2/3 $(\mathbf{b}, \mathbf{e})$,

whereas CAPE prevented the

TGF $\beta 1$-induced nuclear

translocation of SMAD2/3 (c, f).

Scale bar $25 \mu \mathrm{m}$

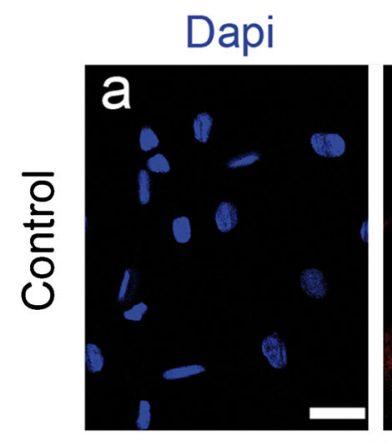

\section{SMAD2/3}
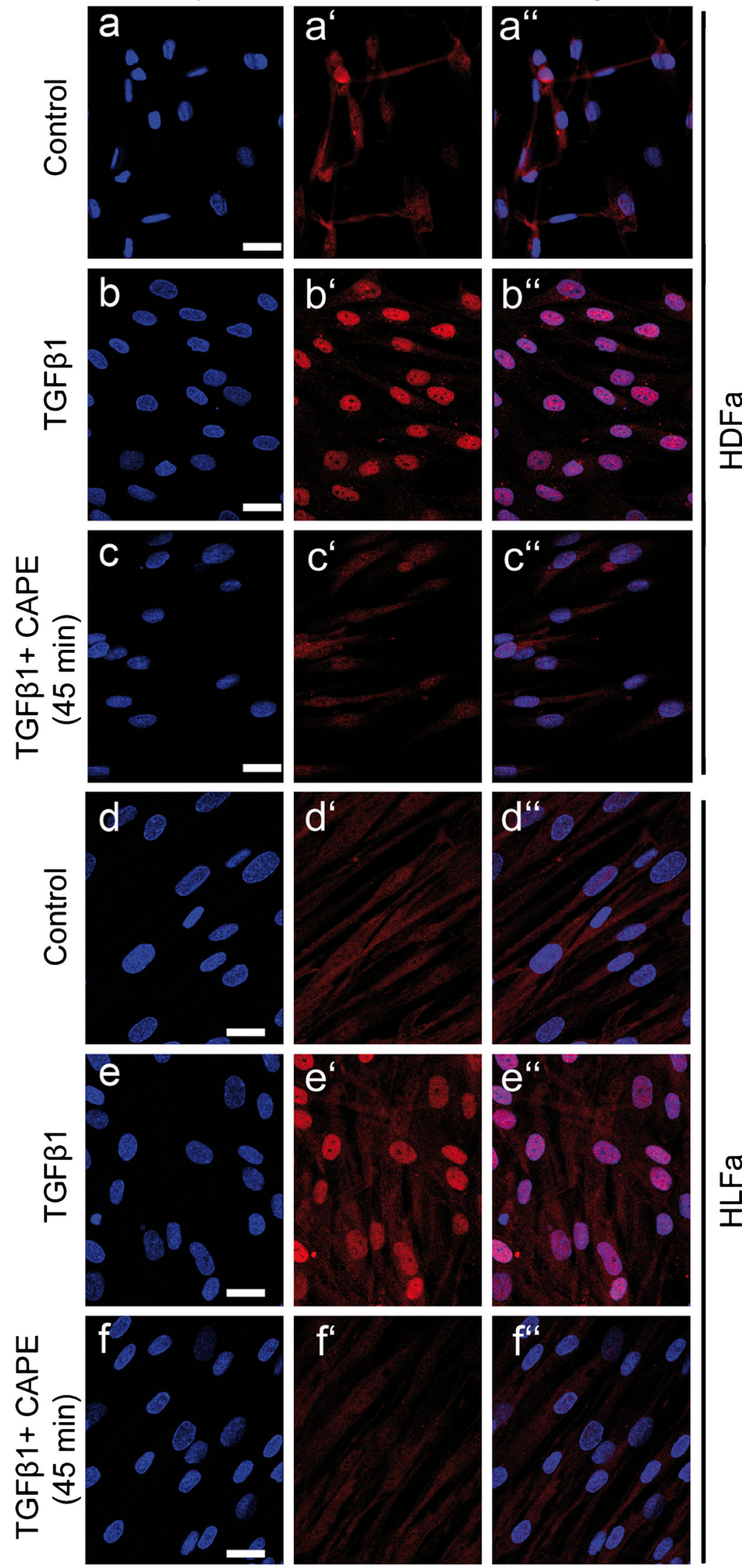
a

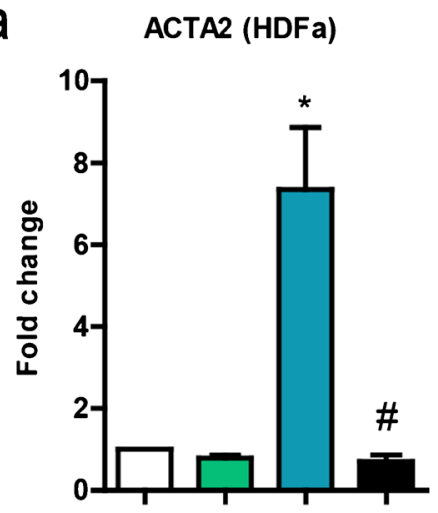

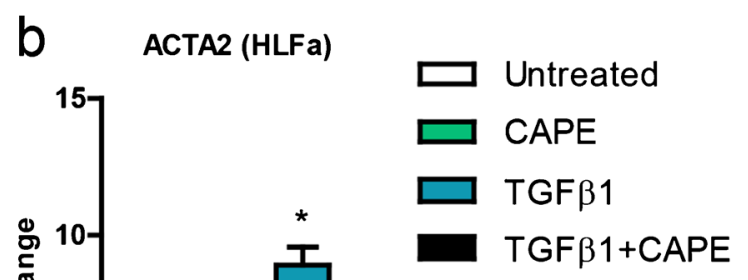

Untreated
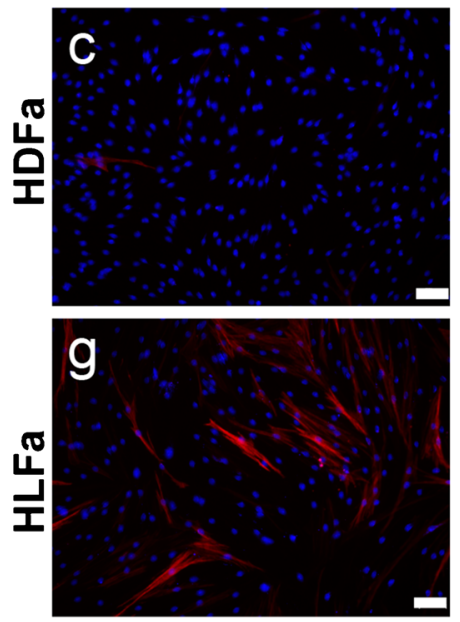

$\mathrm{k}$
CAPE
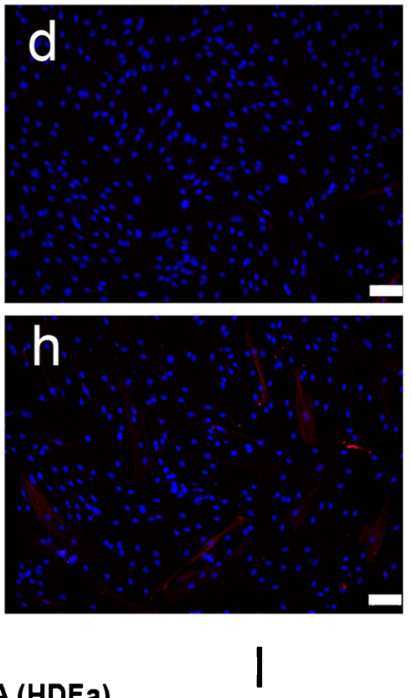

TGF $\beta 1$
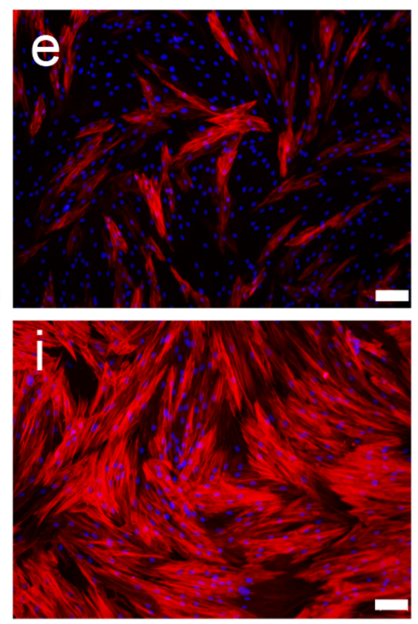

TGF $\beta 1+C A P E$

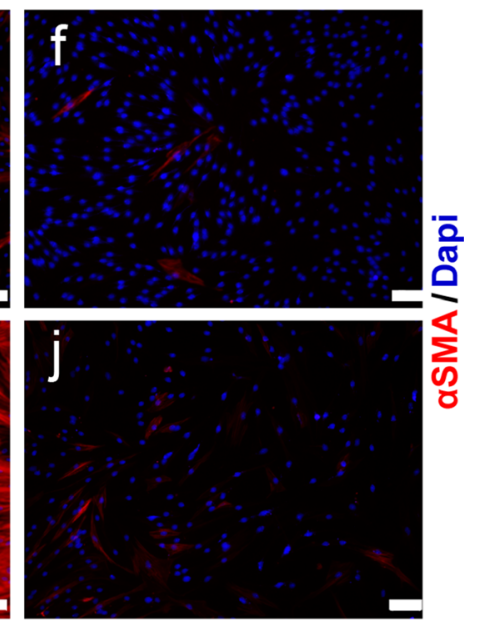

$\alpha$ SMA (HLFa)

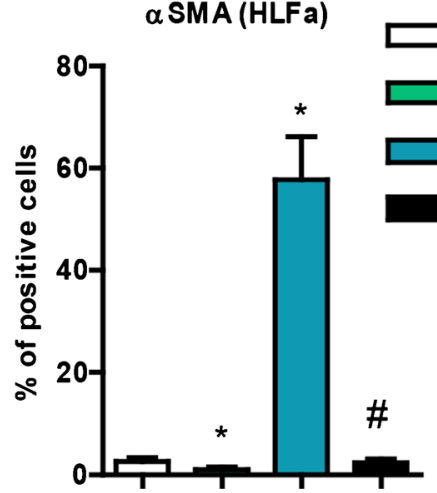

Untreated

CAPE

TGF $\beta 1$

TGF $\beta 1+$ CAPE

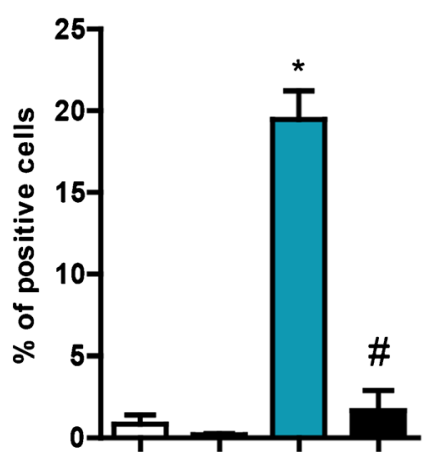

Fig. 3 Effects of CAPE, TGF $\beta 1$ and TGF $\beta 1+$ CAPE on $A C T A 2$ mRNA levels and $\% \alpha$ SMA-positive cells of HDFa and HLFa. Fibroblasts were cultured for $48 \mathrm{~h}$ in the presence of CAPE alone, TGF $\beta 1$ alone, or TGF $\beta 1$ in combination with CAPE (co-treatment). a, b mRNA levels of $A C T A 2$ relative to the reference gene $Y W H A Z$ and expressed as foldchange compared to untreated control (i.e. the baseline level as provided

of mRNA levels of PLOD2 without the presence of TGF $\beta 1$ did not result in an increase of the \% cells that stained positive for LH2. The \% LH2-positive cells increased when stimulated with $\operatorname{TGF} \beta 1$, and increased an additional 1.5- to 2-fold in the presence of CAPE (Fig. 8c-1). in Fig. 1). $\mathbf{c}-\mathbf{j}$ Representative immunofluorescence stainings (upper panel) and $\mathbf{k}, \mathbf{l}$ quantification of the $\%$ of cells (lower panel) positive for $\alpha$ SMA. * Statistically significant towards untreated control, and \# statistically significant for cells co-treated with TGF $\beta 1+$ CAPE towards TGF $\beta 1$-treated cells. Scale bar $100 \mu \mathrm{m}$

Effect of TGF $\beta 1$ and CAPE on fibronectin (FN1) and tenascin $\mathrm{C}$ (TNC) expression

Apart from collagen type I, we also tested the effect of CAPE on the expression and synthesis of the extracellular matrix proteins FN1 and TNC. TGF $\beta 1$ increased the expression of 
Fig. 4 Effects of post-treatment of CAPE on cells treated with TGF $\beta 1$ regarding the $\% \alpha$ SMApositive cells of HDFa and HLFa. Fibroblasts were cultured for $48 \mathrm{~h}$ in the presence of TGF $\beta 1$, followed by a post-treatment with CAPE for $24 \mathrm{~h}$. a-d Representative immunofluorescence stainings (upper panel) and $\mathbf{e}, \mathbf{f}$ quantification of the $\%$ of cells (lower panel) positive for $\alpha \mathrm{SMA}$ \# Statistically significant for cells post-treated with CAPE towards cells stimulated with TGF $\beta 1$ only. Scale bar $100 \mu \mathrm{m}$

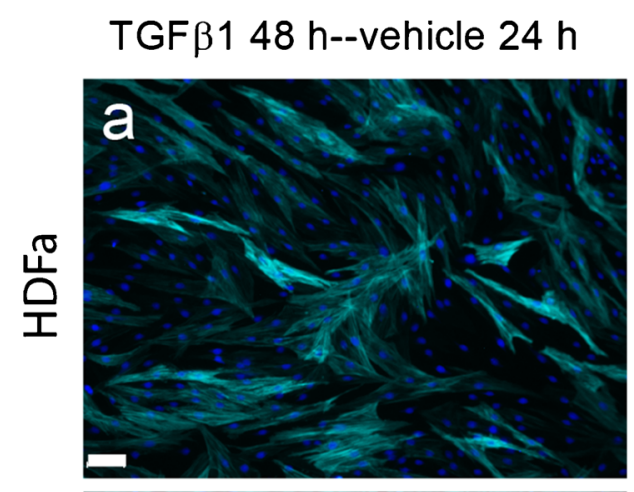

TGF $\beta 148$ h--CAPE $24 \mathrm{~h}$
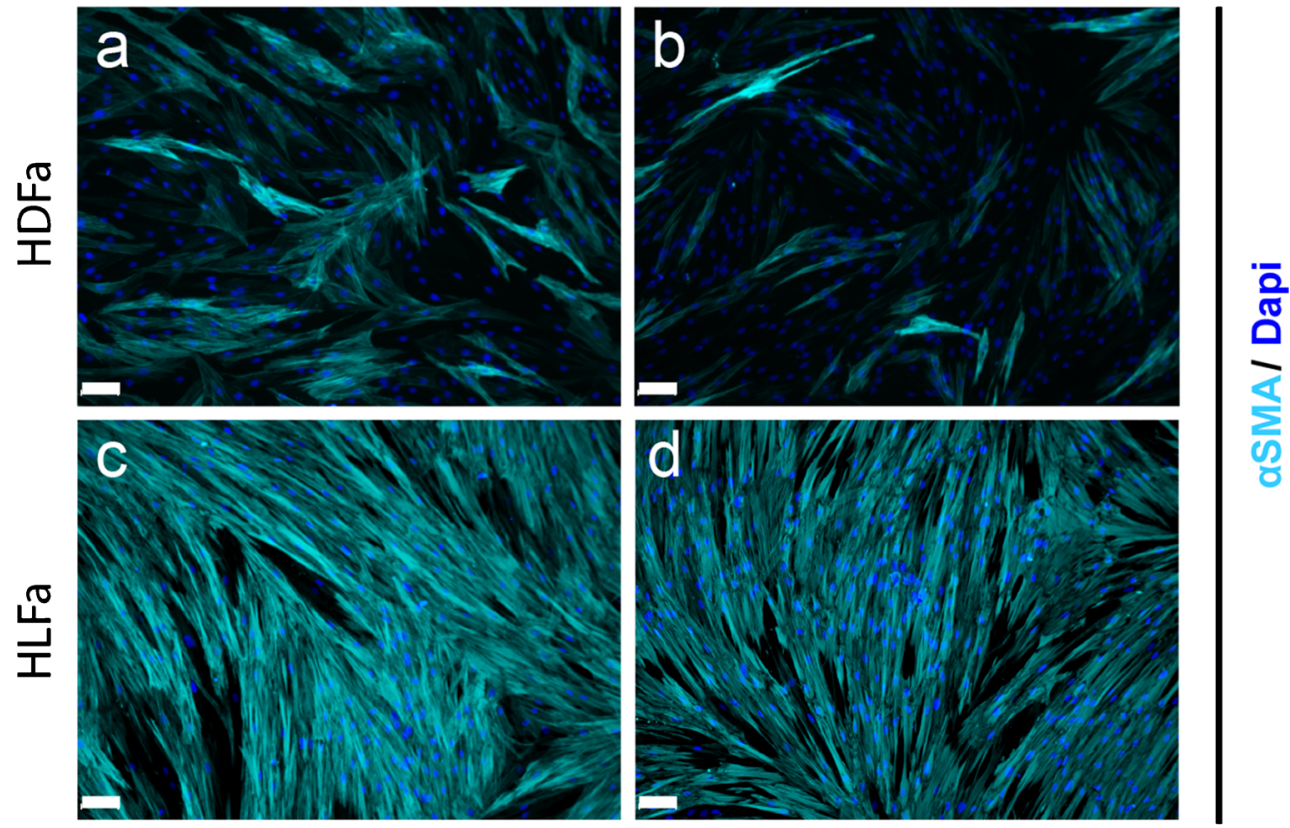

e

a SMA (HDFa)
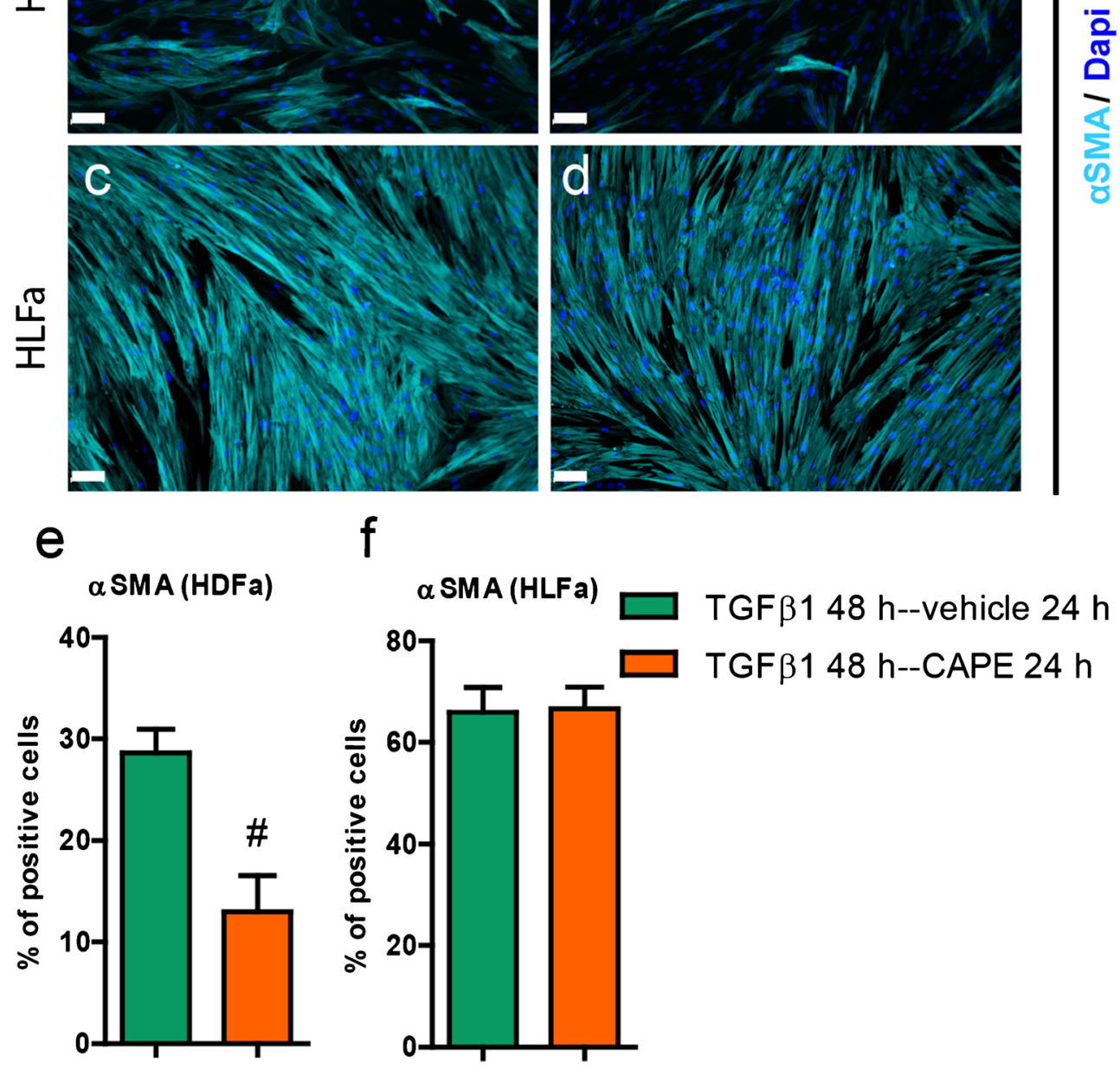

FN1 and TNC in HFDa and HLFa (Fig. 9a-d), an upregulation that was suppressed to baseline levels by CAPE (Fig. 9a-d). The same was seen with respect to the \% cells that stained positive for FN1 and TNC (data not shown).

\section{Effect of TGF $\beta 1$ on GLI, GLI2 and SNAIL1}

The presence of the transcription factors GLI1 and GLI2 are required for myofibroblast formation. As expected, expression of GLI1 and GLI2 was upregulated in the presence of TGF $\beta 1$ : $>20$-fold and 3-fold in HDFa, respectively (Fig. 10a, c), and about 4-fold and 2.5-fold in HLFa, respectively (Fig. 10b, d). The presence of CAPE during TGF $\beta 1$ stimulation had a major inhibitory effect on TGF $\beta 1$-induced upregulation of GLI1 and GLI2 (Fig. 10a-d). The transcription factor SNAIL1 was also upregulated in the presence of TGF $\beta 1$ : a 6-fold and 4-fold induction was seen for HDFa and HLFa, respectively. Remarkably, the presence of CAPE during TGF $\beta 1$ stimulation resulted in an even higher upregulation of SNAIL1 in HDFa, whereas a downregulation was seen in HLFa (Fig. 10e, f).

\section{Discussion}

A generally accepted model to mimic fibrotic events in vitro is the stimulation of fibroblasts with TGF $\beta 1$, a cytokine that shows strong pro-fibrotic properties. TGF $\beta 1$ stimulates the synthesis of collagen, and also differentiates fibroblasts into myofibroblasts. Although CAPE has been found to inhibit fibrosis in vivo in rodents, very little is known about whether 
a

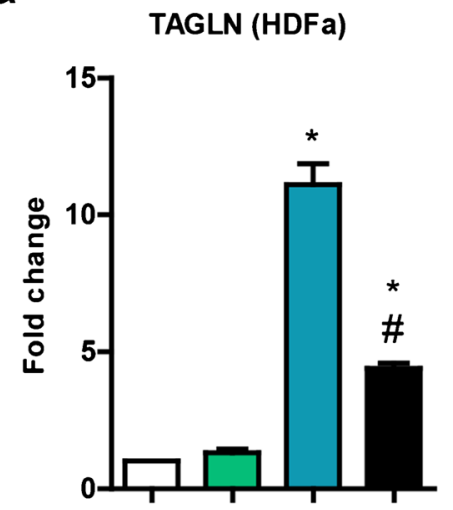

b

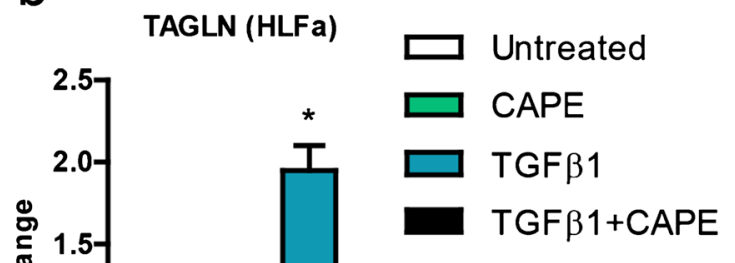

Untreated
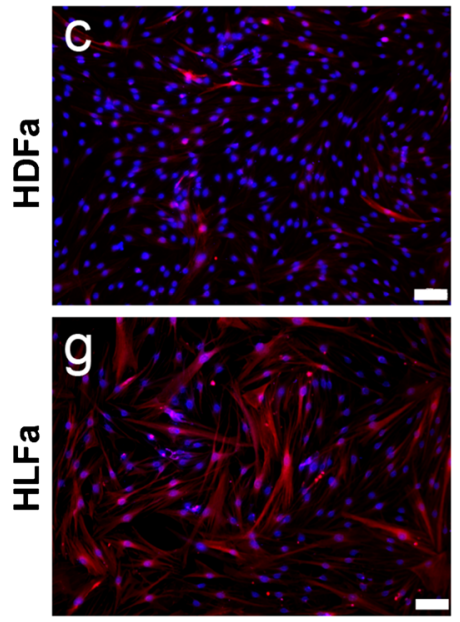

$\mathrm{k}$

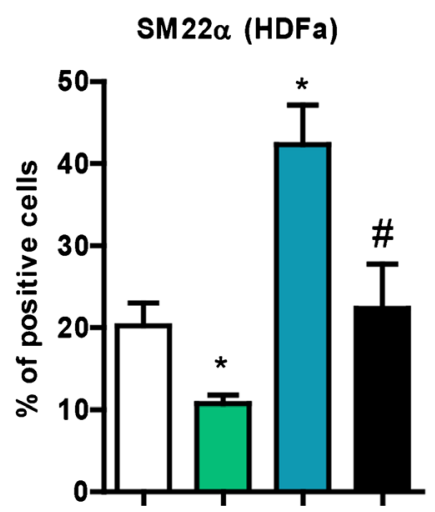

CAPE
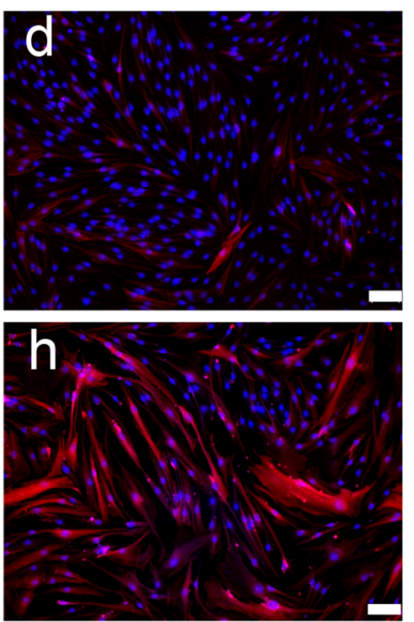
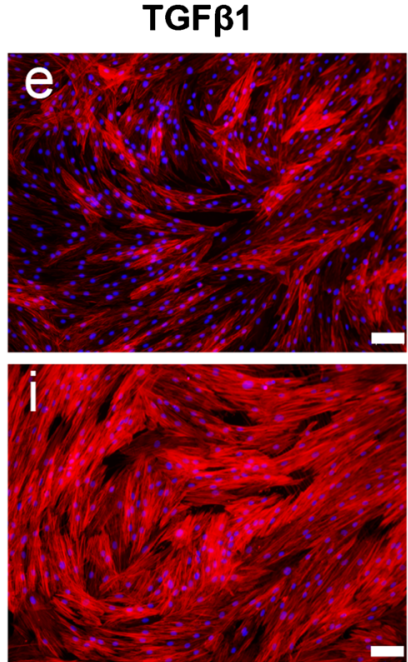

TGF $\beta 1+C A P E$
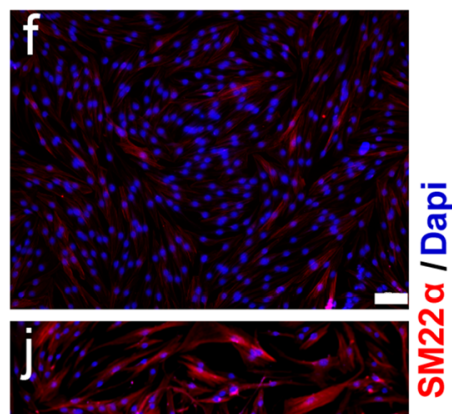

Fig. 5 Effects of CAPE, TGF $\beta 1$ and TGF $\beta 1+$ CAPE on TAGLN mRNA levels and $\%$ SM $22 \alpha$-positive cells of HDFa and HLFa. Fibroblasts were cultured for $48 \mathrm{~h}$ in the presence of CAPE alone, TGF $\beta 1$ alone, or TGF $\beta 1$ in combination with CAPE (co-treatment). a, b mRNA levels of TAGLN relative to the reference gene $Y W H A Z$ and expressed as foldchange compared to untreated control (i.e. the baseline level as provided

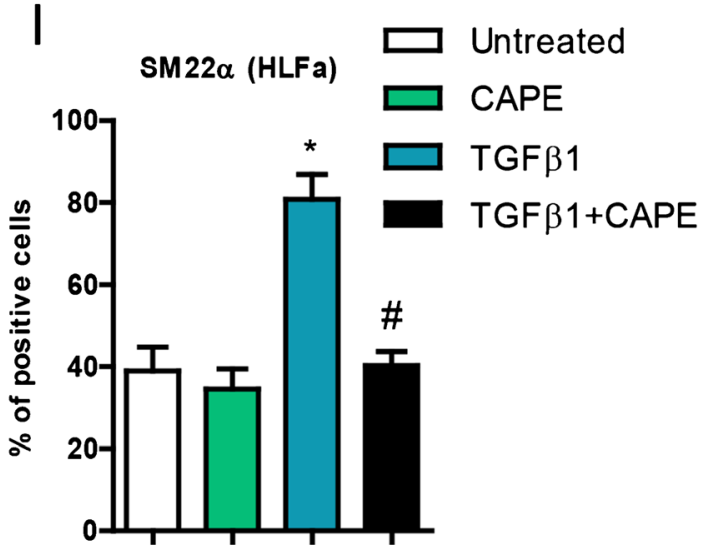

in Fig. 1). c-j Representative immunofluorescence stainings (upper panel) and $\mathbf{k}, \mathbf{l}$ quantification of the $\%$ of cells (lower panel) positive for SM22 $\alpha$. * Statistically significant towards untreated control, and \# statistically significant for cells co-treated with TGF $\beta 1+$ CAPE towards TGF $\beta 1$-treated cells. Scale bar $100 \mu \mathrm{m}$

collagen type I (as revealed by a major increase in the number of cells stained positive for collagen), and that co-incubation with CAPE entirely blocks both fibrotic hallmarks. Thus, CAPE has strong anti-fibrotic properties towards fibroblasts.
CAPE has direct anti-fibrotic properties on fibroblasts. Here, we show that human dermal and lung fibroblasts treated with TGF $\beta 1$ result in high numbers of myofibroblasts (i.e. cells that show $\alpha \mathrm{SMA}$ ) and considerable protein production of 


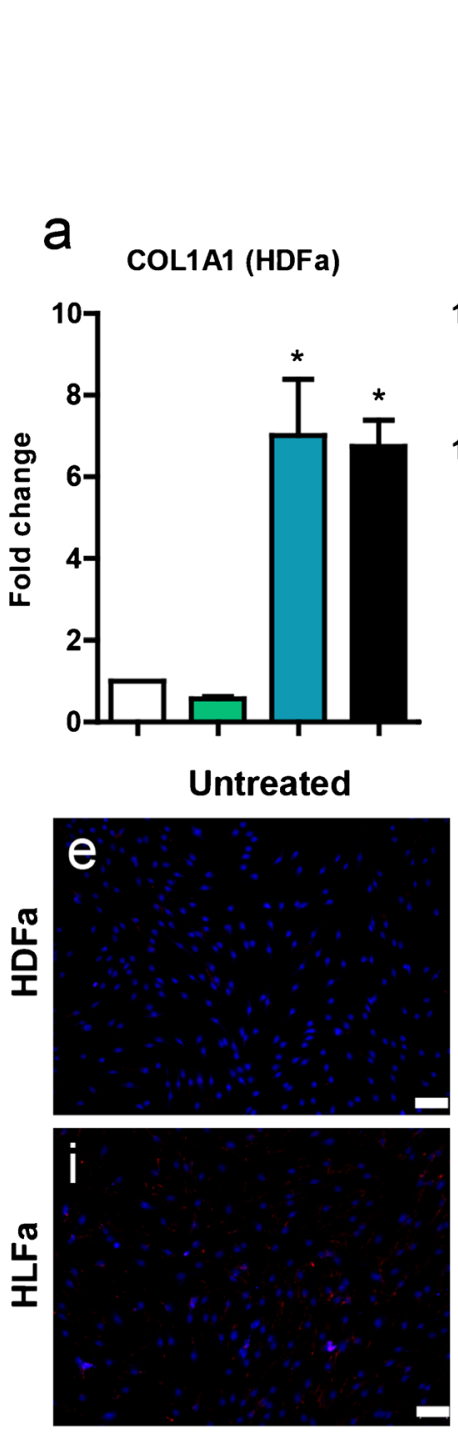

$\mathrm{m}$

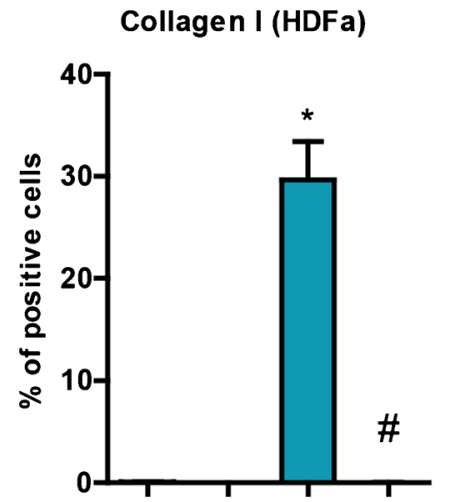

Fig. 6 Effects of CAPE, TGF $\beta 1$ and TGF $\beta 1+$ CAPE on COL1A1 and COL1A2 mRNA levels and \% collagen type I-positive cells of HDFa and HLFa. Fibroblasts were cultured for $48 \mathrm{~h}$ in the presence of CAPE alone, TGF $\beta 1$ alone, or TGF $\beta 1$ in combination with CAPE (co-treatment). a-d mRNA levels of COL1A1 and COL1A2 relative to the reference gene $Y W H A Z$ and expressed as fold-change compared to untreated control
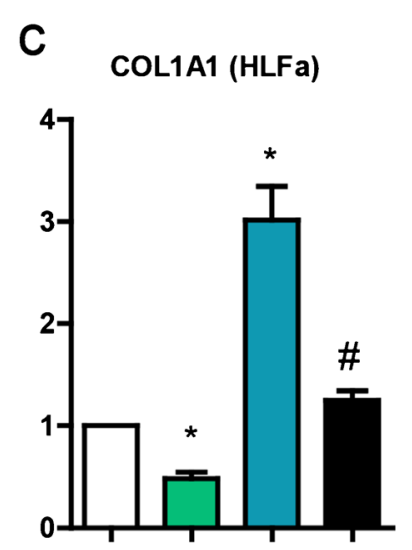

\section{TGF $\beta 1$}
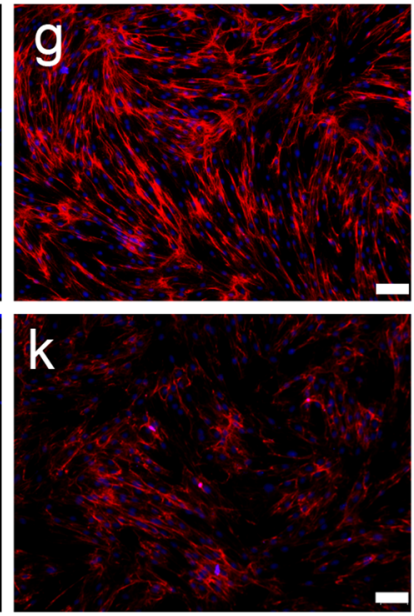

$\mathrm{n}$

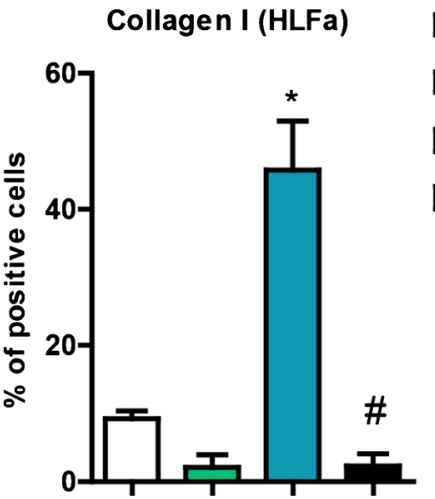

$\square$ Untreated

$\square$ CAPE

$\square$ TGF $\beta 1$

TGF $\beta 1+C A P E$ $\square$ Untreated

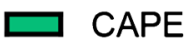

$\square$ TGF $\beta 1$

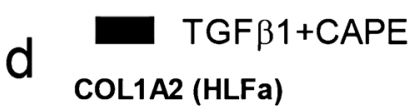
COL1A2 (HLFa)

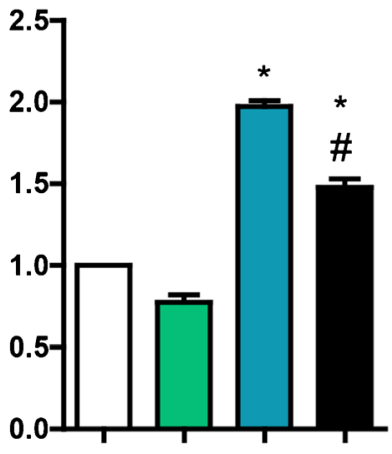

TGF $\beta 1+C A P E$

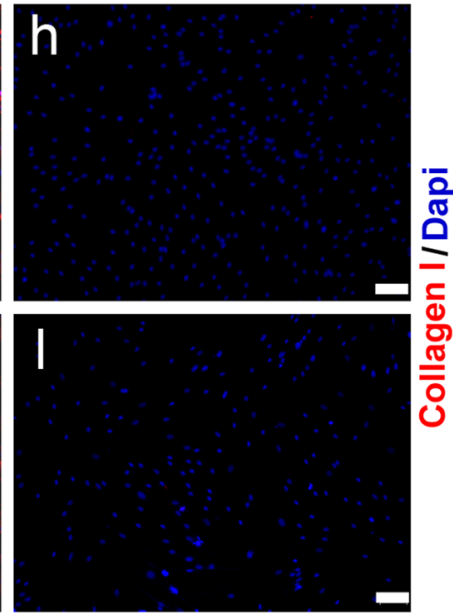

(i.e. the baseline level as provided in Fig. 1). e-l Representative immunofluorescence stainings (upper panel) and $\mathbf{m}, \mathbf{n}$ quantification of the $\%$ of cells (lower panel) positive for collagen type I. * Statistically significant towards untreated control, and \# statistically significant for cells co-treated with TGF $\beta 1+$ CAPE towards TGF $\beta 1$-treated cells. Scale bar $100 \mu \mathrm{m}$ 
Fig. 7 Effects of post-treatment of CAPE on cells treated with TGF $\beta 1$ regarding the $\%$ collagen type I-positive cells of $\mathrm{HDFa}$ and HLFa. Fibroblasts were cultured for $48 \mathrm{~h}$ in the presence of TGF $\beta 1$, followed by a posttreatment with CAPE for $24 \mathrm{~h}$. ad Representative immunofluorescence stainings (upper panel) and $\mathbf{e}, \mathbf{f}$ quantification of the $\%$ of cells (lower panel) positive for collagen type I. \# Statistically significant for cells post-treated with CAPE towards cells stimulated with TGF $\beta 1$ only. Scale bar $100 \mu \mathrm{m}$

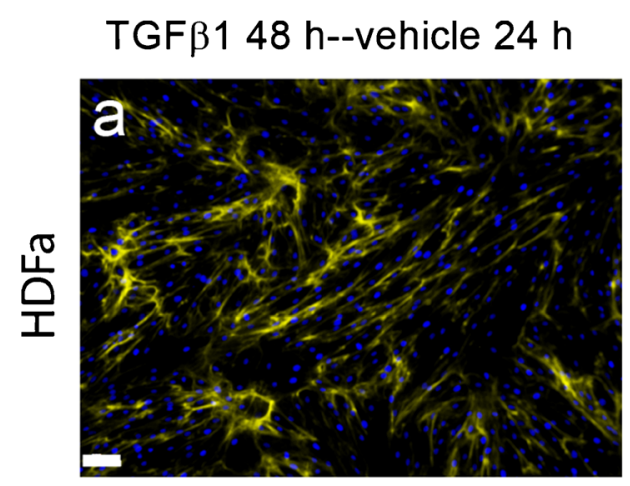

TGF $\beta 148$ h--CAPE $24 \mathrm{~h}$
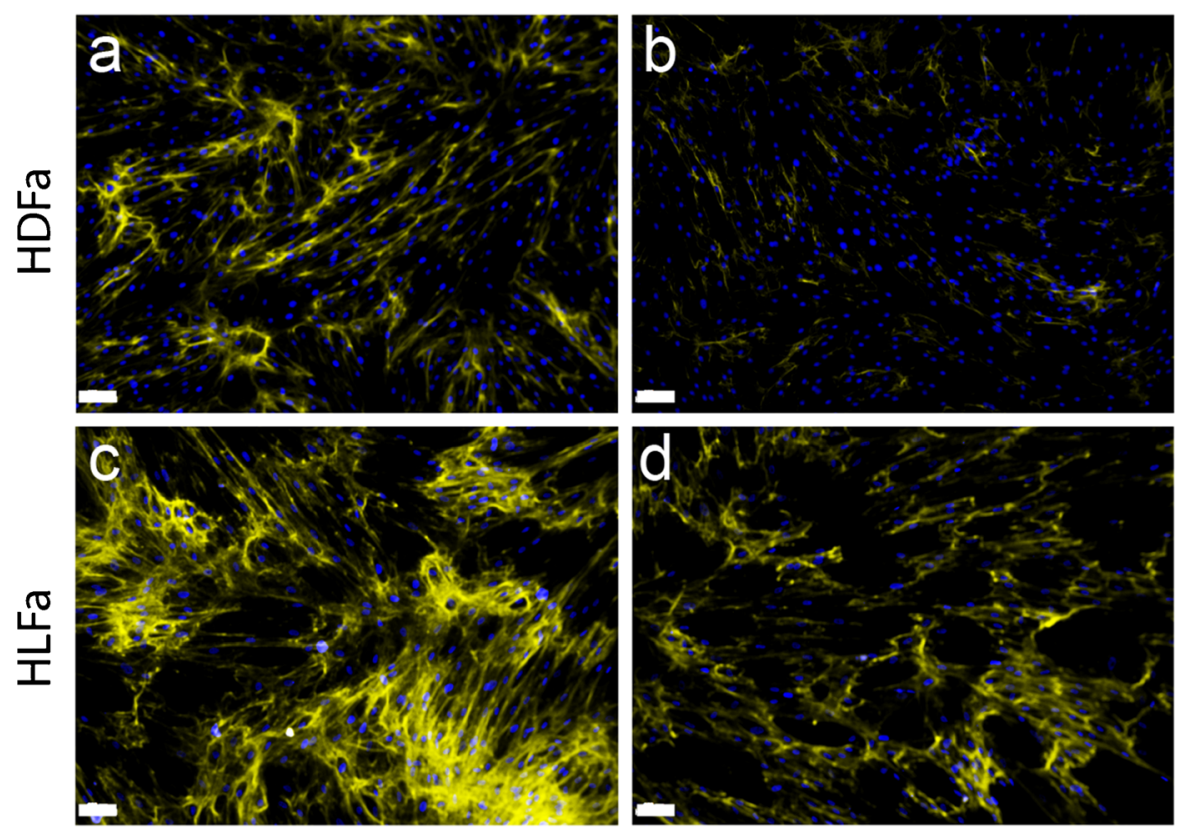

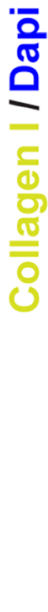

\section{e}

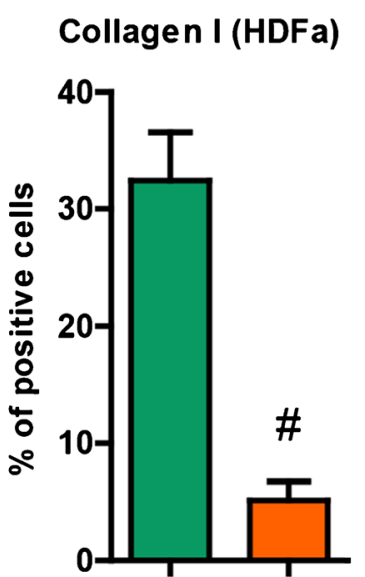

\section{$f$}

\section{Collagen I (HLFa)}

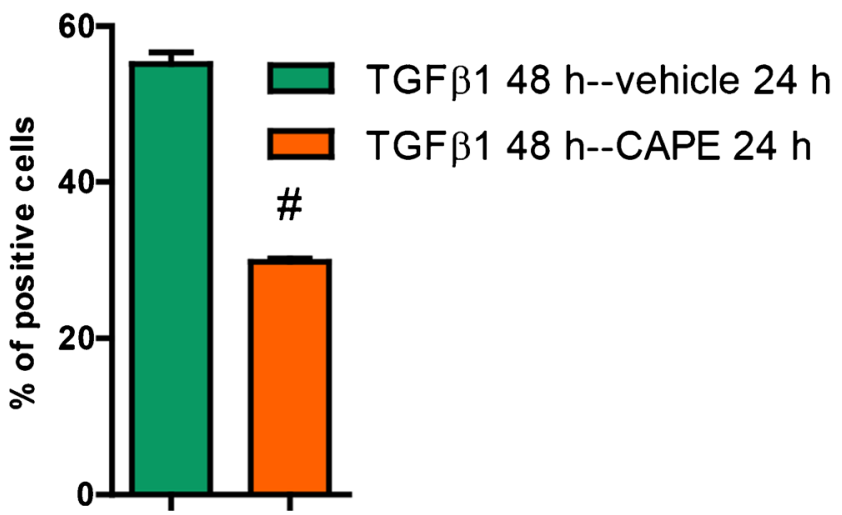

This statement can even be made despite the high increase in PLOD2 mRNA levels (and LH2 protein synthesis). LH2 is a major pro-fibrotic enzyme as it plays a role in the formation of hydroxylysine-derived collagen cross-links (van der Slot et al. 2003, 2004, 2005a). Collagens containing this type of crosslinks are especially difficult to degrade (van der Slot et al. 2005b; Brinckmann et al. 2005). However, in the presence of CAPE, hardly any collagen is produced.

We next investigated whether CAPE is able to reverse myofibroblasts into fibroblasts, and if this is reflected in decreased expression levels of collagen. Remarkable differences were seen between HDFa and HLFa: post-treatment with CAPE showed a 2-fold decrease in $\alpha$ SMA-positive cells in $\mathrm{HDFa}$, whereas no decrease was seen in $\alpha \mathrm{SMA}$-positive cells in HLFa. However, in both cases, a decrease is seen in the \% collagen-positive cells: a 5-fold decrease was observed for HDFa, and a 2-fold decrease for HLFa. It is of importance to note that CAPE thus has the capacity to partially reverse myofibroblasts into fibroblasts (in the case of $\mathrm{HDFa}$ ) and/or partially inhibit collagen formation by myofibroblasts (in the case of HLFa). Reversal of myofibroblasts to fibroblasts has so far only been described for a few compounds (Yang et al. 2014). The data of HLFa show that a decrease in collagen formation can occur despite unchanged levels of $\alpha$ SMA stress fibers. Indeed, the relationship between $\alpha \mathrm{SMA}$ and collagen is not $1: 1$, as it has been shown that $\alpha \mathrm{SMA}^{-/-}$myofibroblasts are still able to produce collagen (Takeji et al. 2006).

Since the presence of GLI1 and GLI2 is necessary for myofibroblast formation, and CAPE is able to inhibit myofibroblast formation as induced by TGF $\beta 1$, we wondered 
a

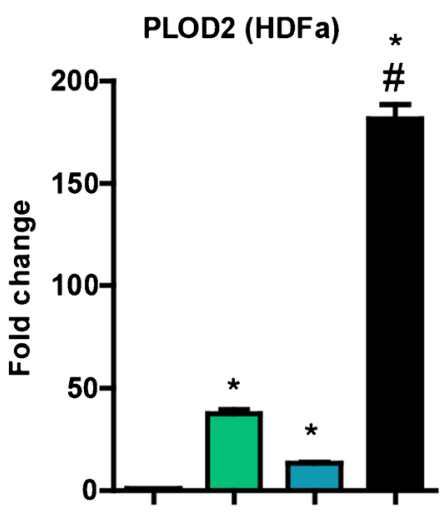

b

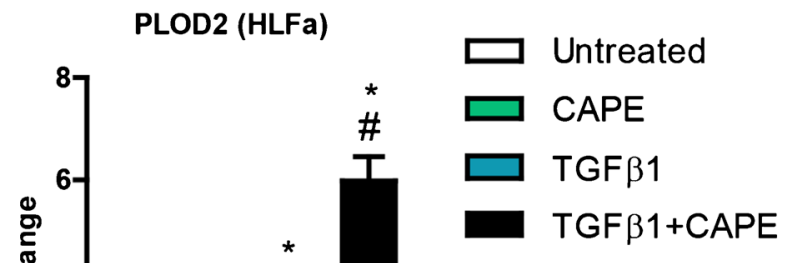

\section{Untreated}
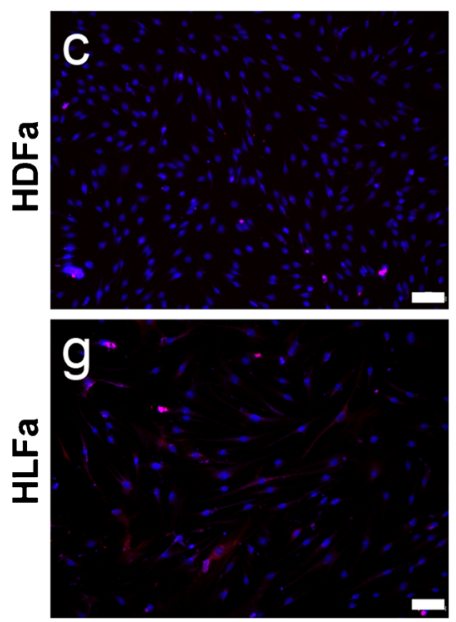

k
CAPE
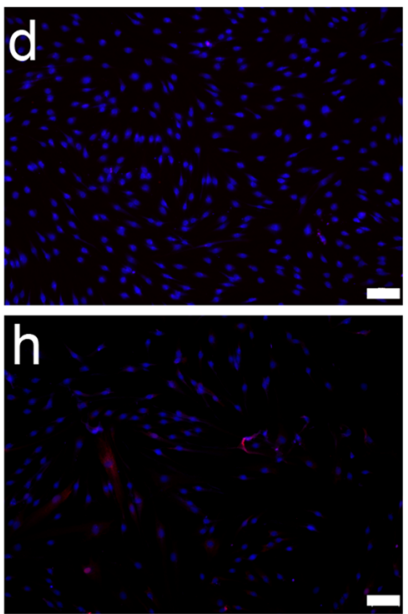

LH2 (HDFa)

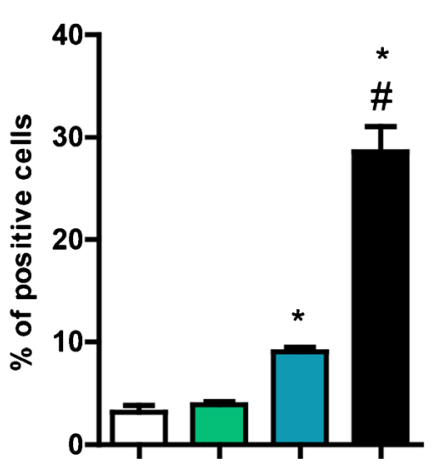

TGF $\beta 1$
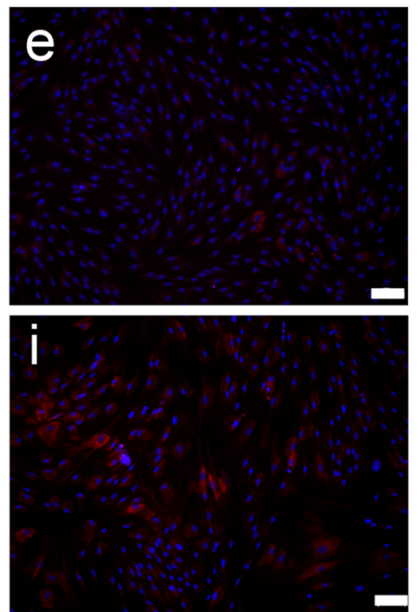

I

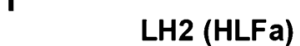

LH2 (HLFa)
TGF $\beta 1+C A P E$

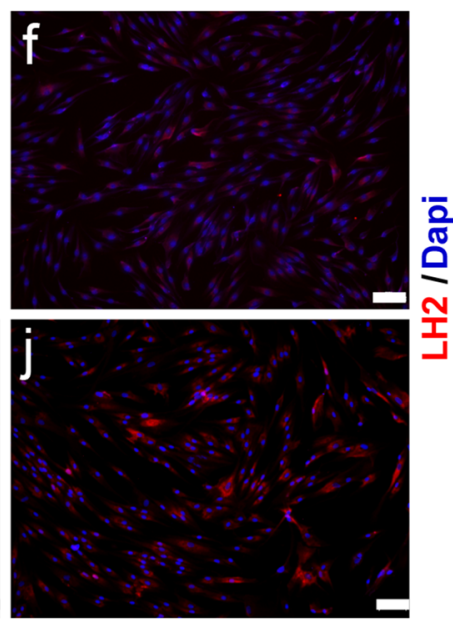

Untreated

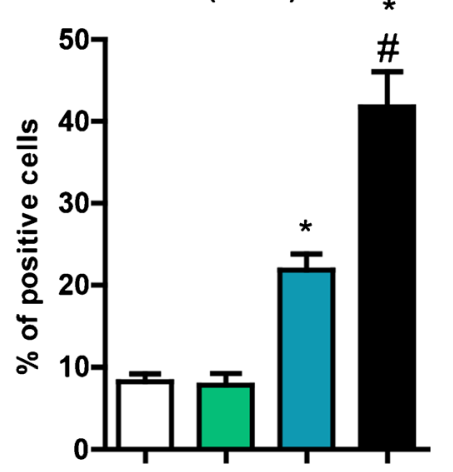

$\square$ CAPE

$\square$ TGF $\beta 1$
TGF $\beta 1+C A P E$
Fig. 8 Effects of CAPE, TGF $\beta 1$ and TGF $\beta 1+$ CAPE on PLOD2 mRNA levels and \% LH2-positive cells of HDFa and HLFa. Fibroblasts were cultured for $48 \mathrm{~h}$ in the presence of CAPE alone, TGF $\beta 1$ alone, or TGF $\beta 1$ in combination with CAPE (co-treatment). a, b mRNA levels of PLOD2 relative to the reference gene $Y W H A Z$ and expressed as foldchange compared to untreated control (i.e. the baseline level as provided in Fig. 1). c-j Representative immunofluorescence stainings (upper panel) and $\mathbf{k}$, I quantification of the $\%$ of cells (lower panel) positive for LH2. * Statistically significant towards untreated control, and \# statistically significant for cells co-treated with TGF $\beta 1+$ CAPE towards TGF $\beta 1$-treated cells. Scale bar $100 \mu \mathrm{m}$

expression as conducted by TGF $\beta$ requires GLI2 (Dennler et al. 2007). The decrease of GLI2 as seen in the presence of CAPE is therefore likely to be related to the low levels of SMAD3 in the nucleus, as observed by confocal laser 
a

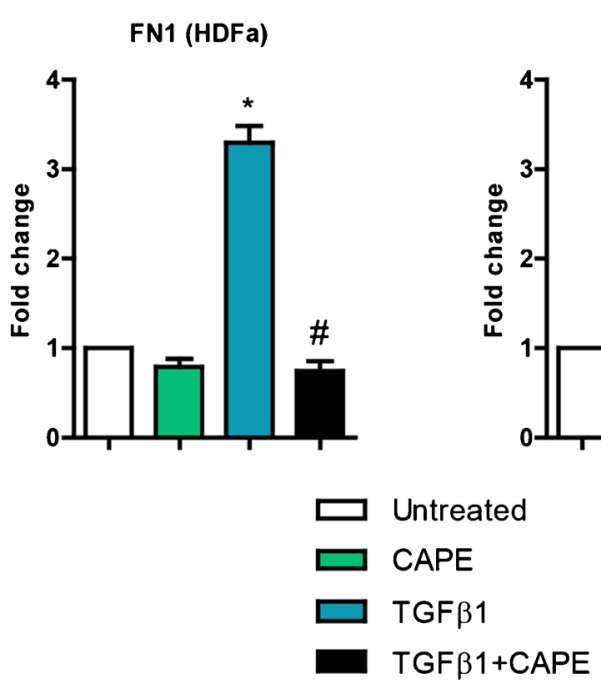

C TNC (HDFa)

d

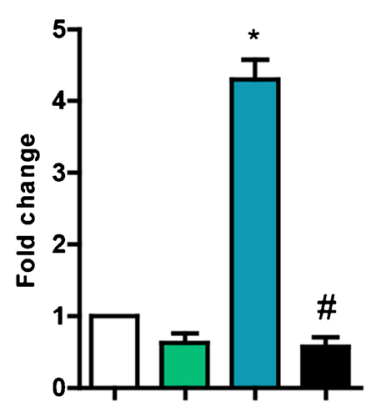

Fig. 9 Effects of TGF $\beta 1$ and CAPE on fibronectin $(F N 1)$ and tenascin C (TNC) gene expression. a-d Fibroblasts were cultured for $48 \mathrm{~h}$ in the presence of CAPE alone, TGF $\beta 1$ alone, or TGF $\beta 1$ in combination with CAPE (co-treatment) on mRNA levels of $F N 1$ and $T N C$ relative to the reference gene $Y W H A Z$ and expressed as fold-change compared to untreated control. * Statistically significant towards untreated control, \# statistically significant for cells co-treated with TGF $\beta 1+$ CAPE towards TGF $\beta 1$-treated cells

scanning microscopy. In addition, it is reasonable to assume that the decrease of GLI1 in the presence of CAPE is a consequence of diminished levels of GLI2, as GLI1 acts downstream of GLI2.

The binding of GLI1 and GLI2 to their DNA targets can be blocked by the compound GANT61 (Lauth et al. 2007). Fibroblasts stimulated with TGF $\beta 1$ in the presence of GANT61 did not show myofibroblast formation, collagen formation was not upregulated, and $\alpha$ SMA stress fiber formation was not observed (Cigna et al. 2012). In our studies with CAPE, we observed the same, and it coincided with the suppression of GLI1 and GLI2 expression to baseline levels. It is therefore tempting to speculate that the observations with CAPE regarding collagen type I and $\alpha \mathrm{SMA}$ can at least be partially ascribed to the ability of CAPE to suppress GLI1 and GLI2 expression. On the other hand, posttreatment studies with GANT61 on TGF $\beta 1$-stimulated a

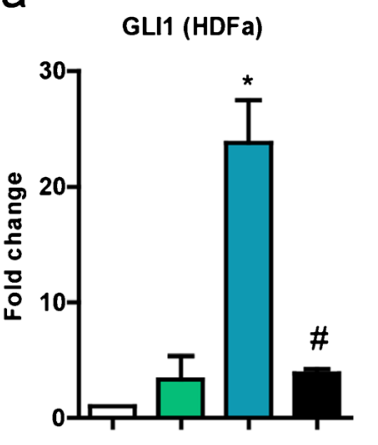

b

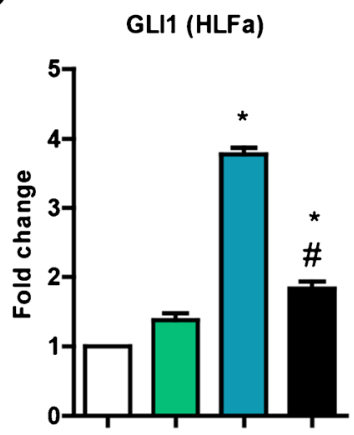

C

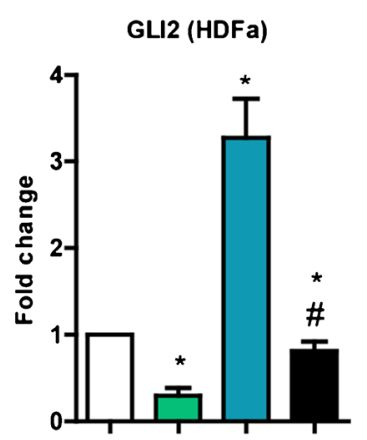

e

SNAIL1 (HDFa)

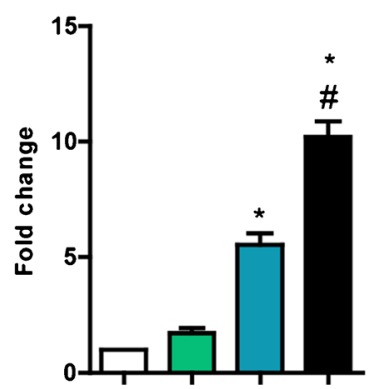

d

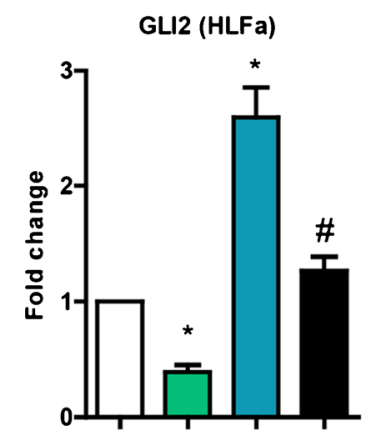

f

SNAL1 (HLFa)

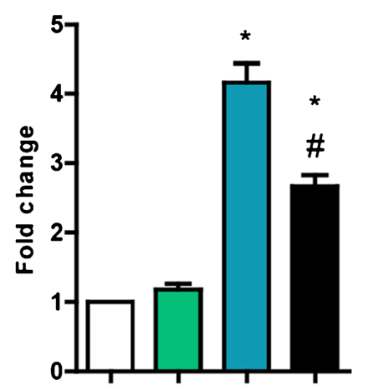

Fig. 10 Effects of CAPE, TGF $\beta 1$ and TGF $\beta 1+$ CAPE on GLII, GLI2 and SNAIL1 mRNA levels of HDFa and HLFa. a-f Fibroblasts were cultured for $48 \mathrm{~h}$ in the presence of CAPE alone, TGF $\beta 1$ alone, or TGF $\beta 1$ in combination with CAPE (co-treatment) on mRNA levels of GLII, GLI2 and SNAIL1 relative to the reference gene YWHAZ and expressed as fold-change compared to untreated control (i.e. the baseline level as provided in Fig. 1). * Statistically significant towards untreated control, \# statistically significant for cells co-treated with TGF $\beta 1+$ CAPE towards TGF $\beta 1$-treated cells

fibroblasts showed a complete reversal of myofibroblasts into fibroblasts, as revealed by an inhibition of collagen type I formation and the absence of $\alpha \mathrm{SMA}$ stress fibers (although protein levels of $\alpha$ SMA were hardly affected) (Cigna et al. 2012). In 
contrast, post-treatment with CAPE did not completely reverse collagen production (both for HDFa and HLFa) and stress fiber formation (for $\mathrm{HDFa}$ ), or did not reverse stress fiber formation at all (for HLFa). Thus, the post-treatment as seen with CAPE does not follow the same pattern of GANT61 post-treatment, which can be explained by assuming that the remaining GLI1 and GLI2 levels are still (partially) capable of binding to their DNA targets.

Our data show that mRNA data of COL1A1 and COL1A2 cannot be used to predict collagen formation. In HDFa, mRNA levels of COL1A1 and COL1A2 remained the same and increased, respectively, when CAPE was added to the TGF $\beta 1$, but the $\%$ cells stained positive for collagen decreased dramatically. The fold-decrease of COL1A1 and COL2A1 in HLFa was also not in line with the fold decrease in the $\%$ collagen-positive cells. Studies regarding the antifibrotic properties of compounds should therefore always take protein data as leading, not mRNA levels, at least with respect to collagen. No conflicting data were observed between mRNA levels and protein data of fibronectin and tenascin C.

Finally, there are major differences in the response of $\mathrm{HDFa}$ and HLFa towards CAPE. For example, when CAPE is added to TGF $\beta 1$, mRNA levels of $C O L 1 A 2$ are even further upregulated, whereas a decrease is seen in HLFa. This was also the case for SNAIL1. In addition, the magnitude of response can differ markedly. mRNA levels of PLOD2 were highly upregulated in $\mathrm{HDFa}$ when CAPE was added to the culture medium, either alone or in combination with TGF $\beta 1$, whereas a modest upregulation of PLOD2 was seen in HLFa. It is well known that there is a high heterogeneity among fibroblast strains, not only between tissues but also within a single tissue (Chang et al. 2002; Sorrell and Caplan 2009). It remains to be investigated whether our data reflect tissue-specific or strain-specific differences; in either case, CAPE was able to inhibit myofibroblast formation.

In conclusion, we show that CAPE has direct anti-fibrotic effects on fibroblasts: it is able to fully counteract the TGF $\beta 1$ induced myofibroblast formation and concomitant collagen formation, and is even able to partially reverse myofibroblasts into fibroblasts and/or partially reverse collagen formation.

\section{Acknowledgments The authors gratefully acknowledge the financial support of the Netherlands Institute for Regenerative Medicine (NIRM, grant No. FES0908) and the Dutch Kidney Foundation.}

Open Access This article is distributed under the terms of the Creative Commons Attribution 4.0 International License (http:// creativecommons.org/licenses/by/4.0/), which permits unrestricted use, distribution, and reproduction in any medium, provided you give appropriate credit to the original author(s) and the source, provide a link to the Creative Commons license, and indicate if changes were made.

\section{References}

Banskota AH, Tezuka Y, Kadota S (2001) Recent progress in pharmacological research of propolis. Phytother Res 15:561-571
Brinckmann J, Kim S, Wu J, Reinhardt DP, Batmunkh C, Metzen E, Notbohm H, Bank RA, Krieg T, Hunzelmann N (2005) Interleukin 4 and prolonged hypoxia induce a higher gene expression of lysyl hydroxylase 2 and an altered cross-link pattern: important pathogenetic steps in early and late stage of systemic scleroderma? Matrix Biol 24:459-468

Chang HY, Chi JT, Duoit S, Bondre C, van de Rijn M, Botstein D, Brown PO (2002) Diversity, topographic differentiation, and positional memory in human fibroblasts. Proc Natl Acad Sci U S A 99: 12877-12782

Chuang ST, Kuo YH, Su MJ (2014) Antifibrotic effects of KS370G, a caffeamide derivative, in renal ischemia-reperfusion injured mice and renal tubular epithelial cells. Sci Rep 4:5814

Chuang ST, Kuo YH, Su MJ (2015) KS370G, a caffeamide derivative, attenuates unilateral obstruction-induced renal fibrosis by the reduction of inflammation and oxidative stress in mice. Eur $\mathrm{J}$ Pharmacol 750:1-7

Chun SW, Park IH, Hong SM, Cho JS, Moon JH, Kim TH, Lee HM (2014) Role of caffeic acid on collagen production in nasal polypderived fibroblasts. Clin Exp Otorhinolaryngo 7:295-301

Cigna N, Moshai EF, Brayer S, Marchal-Somme J, Wémeau-Stervinou L, Fabre A, Mal H, Lesèche G, Dehoux M, Soler P, Crestani B, Mailleux AA (2012) The hedgehog system machinery controls transforming growth factor- $\beta$-dependent myofibroblastic differentiation in humans. Involvement in idiopathic pulmonary fibrosis. Am J Pathol 181:2126-2137

Dennler S, André J, Alexaki I, Li A, Magnaldo T, ten Dijke P, Wang XJ, Verrecchia F, Mauviel A (2007) Induction of sonic hedgehog mediators by transforming growth factor- $\beta$ : Smad3-dependent activation of Gli2 and Gli1 expression in vitro and in vivo. Cancer Res 67: 6981-6986

Dennler S, André J, Verrecchia F, Mauviel A (2009) Cloning of the human GLI2 promoter. transcriptional activation by transforming growth factor- $\beta$ via SMAD3/ $\beta$-catenin cooperation. J Biol Chem 284:31523-31531

Ghosh AK, Quaggin SE, Vaughan DE (2013) Molecular basis of organ fibrosis: potential therapeutic approaches. Exp Biol Med 238:461481

Goldsmith EC, Bradshaw AD, Zile MR, Spinale FG (2014) Myocardial fibroblast-matrix interactions and potential therapeutic targets. J Mol Cell Cardiol 70:92-99

Javelaud D, Alexaki VI, Dennler S, Mohammad KS, Guise TA, Mauviel A (2011) TGF- $\beta /$ SMAD/GLI2 signaling axis in cancer progression and metastasis. Cancer Res 71:5606-5610

Larki A, Hemmati AA, Arzi A, Ghafurian Borujerdnia M, Esmaeilzadeh S, Zad Karami MR (2013) Regulatory effect of caffeic acid phenethyl ester on type I collagen and interferon-gamma in bleomycin-induced pulmonary fibrosis in rat. Res Pharm Sci 8: 243-252

Lauth M, Bergström A, Shimokawa T, Toftgård R (2007) Inhibition of GLI-mediated transcription and tumor cell growth by smallmolecule antagonists. Proc Natl Acad Sci U S A 104:8455-8460

Liu R, Chen H, Bai H, Zhang W, Wang X, Qin X, Zhang X, Li W, Lian X, Hai C (2013) Suppression of nuclear factor erythroid 2-related factor 2 via extracellular signal-regulated kinase contributes to bleomycininduced oxidative stress and fibrogenesis. Toxicol Lett 220:15-25

Mallat A, Lotersztajn S (2013) Cellular mechanisms of tissue fibrosis. 5. novel insights into liver fibrosis. Am J Physiol Cell Physiol 305: C789-C799

Mia MM, Boersema M, Bank RA (2014) Interleukin-1 $\beta$ attenuates myofibroblast formation and extracellular matrix production in dermal and lung fibroblasts exposed to transforming growth factor- $\beta 1$. PLoS ONE 9:e91559

Murtaza G, Karim S, Akram MR, Khan SA, Azhar S, Muntaz A, Bin Ashad MH (2014) Caffeic acid phenethyl ester and therapeutic potentials. Biomed Res Int 2014:145342 
Ogeturk M, Kus I, Colakoglu N, Zarasiz I, Ilhan N, Sarsilmaz M (2005) Caffeic acid phenethyl ester protects kidneys against carbon tetrachloride toxicity in rats. J Ethnopharmacol 97:273-280

Özyurt H, Söğüt S, Yıldırım Z, Kart L, Iraz M, Armutçu F, Temel I, Özen S, Uzun A, Akyol Ö (2004) Inhibitory effect of caffeic acid phenethyl ester on bleomycin-induced lung fibrosis in rats. Clin Chim Acta 339:65-75

Song HA, Park TW, Sohn YD, Shin YK, Choi BC, Kim CJ, Sim SS (2008) The effect of caffeic acid on wound healing in skin-incised mice. Korean J Physiol Pharmacol 12:343-347

Sorrell JM, Caplan AI (2009) Fibroblasts - a diverse population at the center of it all. Int Rev Cell Mol Biol 276:161-214

Takeji M, Moriyama T, Oseto S, Kawada N, Hori M, Imai E, Miwa T (2006) Smooth muscle $\alpha$-actin deficiency in myofibroblasts leads to enhanced renal tissue fibrosis. J Biol Chem 281:40193-40200

Tolba MF, Azab SS, Khalifa AE, Abdel-Rahman SZ, Abdel-Naim AB (2013) Caffeic acid phenethyl ester, a promising component of propolis with a plethora of biological activities: a review on its antiinflammatory, neuroprotective, hepatoprotective, and cardioprotective effects. IUBMB Life 65:699-709

Tomur A, Kanter M, Gurel A, Erboga M (2011) The efficiency of CAPE on retardation of hepatic fibrosis in biliary obstructed rats. J Mol Hist 42:451-458

van der Slot AJ, Zuurmond AM, Bardoel AFJ, Wijmenga C, Pruijs HEH, Sillence DO, Brinckmann J, Abraham DJ, Black CM, Verzijl N, DeGroot J, Hanemaaijer R, TeKOppele JM, Huizinga TWJ, Bank RA (2003) Identification of PLOD2 as telopeptide lysyl hydroxylase, an important enzyme in fibrosis. J Biol Chem 278: 40967-40972

van der Slot AJ, Zuurmond AM, van den Bogaerdt AJ, Ulrich MM, Middelkoop E, Boers W, Ronday HK, DeGroot J, Huizinga TW, Bank RA (2004) Increased formation of pyridinoline cross-links due to higher telopeptidyl lysyl hydroxylase levels is a general fibrotic phenomenon. Matrix Biol 23:251-257

van der Slot AJ, van Dura EA, de Wit EC, DeGroot J, Huizinga TW, Bank RA, Zuurmond AM (2005a) Elevated formation of pyridinoline cross-links by profibrotic cytokines is associated with enhanced lysyl hydroxylase 2b levels. Biochim Biophys Acta 1741:95-102

van der Slot AJ, Dura EA, Attema J, Blauw B, DeGroot J, Huizinga TW, Zuurmond AM, Bank RA (2005b) The type of collagen cross-link determines the reversibility of experimental skin fibrosis. Biochim Biophys Acta 1740:60-67

Yamauchi M, Sricholpech M (2012) Lysine post-translational modifications of collagen. Essays Biochem 52:113-133

Yang XH, Chen B, Liu T, Chen XH (2014) Reversal of myofibroblast differentiation: a review. Eur J Pharmacol 734:83-90

Yue P, Shan B, Lasky JA (2010) TGF- $\beta$ : Titan of lung fibrogenesis. Curr Enzym Inhib 6:doi 10.2174/10067

Zhao WX, Zhao J, Linag CL, Zhao B, Pang RQ, Pan XH (2003) Effect of caffeic acid phenethyl ester on proliferation and apoptosis of hepatic stellate cells in vitro. World J Gastroenterol 9:1278-1281

Zhao WX, Wang L, Yang JL, Li LZ, Xu WM, Li T (2014) Caffeic acid phenethyl ester attenuates pro-inflammatory and fibrogenic phenotypes of LPS-stimulated hepatic stellate cells through the inhibition of NF-кB signaling. Int J Mol Med 33:687-694 